Knowing me, Knowing us: Personal and Collective Self-Awareness Enhances Authentic Leadership and Leader Endorsement

Niklas K. Steffens ${ }^{1, *}$, Nathan Wolniec ${ }^{1}$, Tyler G. Okimoto ${ }^{2}$, Frank Mols ${ }^{3}$, S. Alexander Haslam $^{1}$, Adam A. Kay ${ }^{2}$

${ }^{1}$ School of Psychology, The University of Queensland, Brisbane, QLD 4072, Australia

${ }^{2}$ UQ Business School, The University of Queensland, Brisbane, QLD 4072, Australia

${ }^{3}$ School of Political Science and International Studies, The University of Queensland, Brisbane, QLD 4072, Australia

* Corresponding author: Nik Steffens, School of Psychology, The University of Queensland, Brisbane, QLD 4072, Australia; Tel: +(0) 6173364 9555; Email: n.steffens@uq.edu.au.

Accepted (uncorrected) manuscript for publication in The Leadership Quarterly:

Steffens, N. K. \& Wolniec, N., Okimoto, T. G., Mols, F., Haslam, S. A., \& Kay, A. K. (2021). Knowing me, knowing us: Personal and collective self-awareness enhances authentic leadership and leader endorsement. The Leadership Quarterly. Advance online publication.

This version is the accepted (uncorrected) version, not the final record, and may not exactly replicate the final version of the article.

Author Note. This research was supported by grant (DE180100676) from the Australian Research Council awarded to the first author. We thank Alexandria Macdade for help with data collection for Study 3.

Supplementary Materials: Data, analysis code, and experimental manipulations are accessible on the open science framework: https://osf.io/fc8us/. 


\begin{abstract}
In the present research, we examine how two aspects of leader self-awareness - namely, leader awareness of their (a) personal identity and (b) collective (group) identity — influence perceptions of authentic leadership and leader endorsement. Study 1 provides experimental evidence that (a) leader personal self-awareness has a somewhat stronger impact on perceptions of their authentic leadership than leader collective self-awareness, but that (b) leader collective self-awareness self has a stronger impact on leader endorsement. These findings are replicated in a second field study with political leaders, and in a third experimental study with workplace supervisors. Results suggest that for leaders to seen as authentic and garner support, they need to be seen as aware not only of who they are as individuals, but also of who they are as members of the collective they seek to lead. Implications for theories of the nature of self, authenticity, and leadership are discussed.
\end{abstract}




\section{Knowing me, Knowing us: Personal and Collective Self-Awareness Enhances Authentic Leadership and Leader Endorsement}

By her tenth year as Chancellor of Germany, Angela Merkel had cultivated an image of herself as "the mother of the nation" and was lauded as de facto leader of the European Union (Vick \& Shuster, 2015). In a climate in which Muslim refugees were fleeing war-torn countries and Hungary (among other neighboring states) was threatening to close its borders, Merkel made what would be one of her most impactful political decisions. Despite backlash from right-wing demonstrators protesting Germany's openness to Muslim refugees, Merkel doubled-down on her open-door policy, staying true to her deep-seated belief in the most basic of human rights: freedom.

Theory and evidence surrounding authentic leadership (as evinced by Angela Merkel) show that authenticity influences a range of positive outcomes among followers, leaders, groups, and organizations (Gardner, Cogliser, Davis, \& Dickens, 2011). Yet despite a substantial increase in scholarly attention to authentic leadership over the last decade, the literature has tended to focus on perceptions of leader authenticity and its consequences for organizational outcomes. In addition, previous work has relied on cross-sectional studies by measuring perceptions of authentic leadership and exploring their correlations with outcomes of interest. As a result, little is known about the factors that determine individuals' (subjective) recognition of authentic leadership in the first place.

In the present research, we seek to advance understanding of the factors that determine whether, and to what extent, individuals perceive leaders to be authentic. For this purpose, we revisit and expand upon the notion of self-awareness, a core element of authentic leadership. In particular, we seek to broaden our understanding of what constitutes selfawareness in organizational contexts by drawing on the self-categorization and identity 
leadership tradition, which recognizes the importance of both personal and collective dimensions of selfhood. More specifically, we examine individual perceptions of the extent to which leaders are aware of their personal self and of their group (collective) self, and we explore how these two notions of selfhood shape perceptions and endorsements of authentic leadership. In so doing, we seek to shed light on the relative importance of these two types of self-awareness for perceptions of leader authenticity and support for leaders. By this means, we advance theory and research on factors that underlie perceptions of authentic leadership, and point to new opportunities for enacting authentic leadership in ways that foster endorsement of leaders and their actions.

\section{The Nature of Authentic Leadership}

The genesis of authenticity can be traced back to the ancient Greek maxim "know thyself' (Parke \& Wormell, 1956), with early notions of authentic behavior focusing on selfinquiry in the pursuit of fulfilment (e.g., self-actualization). According to authentic leadership theory, leaders can be considered authentic when they (a) know who they are and (b) consistently enact their values and beliefs (Gardner et al., 2011). In response to waning confidence in political and corporate leaders (Neider \& Schriesheim, 2011), authentic leadership and its impact on followers has been a topic of substantial interest for practitioners (George, 2010) and scholars alike (for comprehensive reviews see Banks, McCauley, Gardner, \& Guler, 2016; Gardner et al., 2011).

Although authentic leadership has been defined in various ways, most conceptualizations and research espouse the fundamental notion of "being true to one's self" (Ilies, Morgeson, \& Nahrgang, 2005; Chan, Hannah, \& Gardner, 2005; George \& Sims, 2007; Shamir \& Eilam, 2005). In light of this, most research conceptualizes authentic leadership as a general, higher-order factor that incorporates four sub-components: (1) self-awareness (i.e., understanding the impact of how one derives meaning from the world on him/herself), (2) 
relational transparency (i.e., presenting one's true self by openly sharing one's thoughts and feelings), (3) balanced processing (i.e., objectively processing self-relevant data before coming to a decision, while soliciting alternative views to challenge one's deeply help positions), and (4) internalized moral perspective (i.e., self-regulated action guided by internal moral standards and values expressed in decision making and behavior; Neider and Schriesheim, 2011).

Leaders who are perceived to be authentic in these ways are understood to be able to galvanize groups of individuals and inspire a range of positive organizational outcomes, such as (a) improved organizational performance (Clapp-Smith, Vogelgesang, \& Avey, 2009; Hmieleski, Cole, \& Baron, 2012), (b) lower employee burnout (Laschinger \& Fida, 2014; Wong \& Cummings, 2009), (c) higher work engagement and job satisfaction (Giallonardo, Wong, \& Iwasiw, 2010), (d) greater follower creativity (Rego, Sousa, Marques, \& e Cunha, 2012), and (e) higher levels of follower performance (Leroy, Anseel, Gardner, \& Sels, 2015; Wang, Sui, Luthans, Wang, \& Wu, 2014).

\section{Follower Perceptions of Authentic Leadership}

With its rise in popularity, authentic leadership research has benefited from the development of both theoretical models (Chan et al., 2005; Ilies et al., 2005) and validated measurement tools (Neider \& Schriesheim, 2011). However, despite calls for more robust theories of authentic leadership (Cooper, Scandura, \& Schriesheim, 2005; Fields, 2007; Sidani \& Rowe, 2018; Shamir \& Eilam, 2005), the landscape of knowledge has not substantially changed in the two decades since the term 'authentic leadership' was first coined. In particular, while much has been learned about the consequences of authentic leadership, relatively little is understood about the dynamics that shape individual perceptions of leader authenticity. 
In line with this observation, Banks and colleagues' (2016) meta-analyses of 71 published articles on authentic leadership revealed that very few studies provide insight into factors that influence perceptions of leader authenticity. Those studies that do touch on this issue indicate that perceptions of leader authenticity are positively influenced by (a) leaders' self-knowledge and self-consistency (Peus, Wesche, Streicher, Braun, \& Frey, 2012), (b) the consistency between leaders' words and behaviors (Weischer, Weibler, \& Petersen, 2013), and (c) leaders’ own judgments of their authenticity (Černe, Dimovski, Marič, Penger, \& Škerlavaj, 2014). Other work has found that congruence between leader and follower values, as well as follower beliefs in social change, are both positively related to perceptions of authentic leadership (Williams, Pillai, Deptula, \& Lowe, 2012). There is also evidence that perceptions of authenticity are increased not only by leaders acting in ways that are true to their values, but also by leaders acting in a way that is true to the collective vision of the group they lead (Steffens, Mols, Haslam, \& Okimoto, 2016). Yet aside from this work, little work has examined which leader characteristics shape individual perceptions of authentic leadership. Indeed, still missing from authentic leadership theorizing is any sense that authenticity is an inference that people make rather than an intrinsic quality of leaders themselves.

In the present work, we draw on the social identity approach - comprising social identity theory (Tajfel \& Turner, 1979) and self-categorization theory (Turner, 1982; Turner et al., 1987) — to shed light on authentic leadership perceptions. At the core of this body of theorizing is the idea that self-categorization is contingent on social context, such that a person's sense of self is flexible and can be defined at different levels of abstraction (Ashforth, Harrison, \& Corley, 2008; Turner, 1982; Turner, Hogg, Oakes, Reicher, \& Wetherell, 1987). In this way, selfhood is understood to be complex and multi-faceted. At a lower level of abstraction, an individual's personal identity can be defined in terms of an 
idiosyncratic combination of characteristics that makes them a unique individual (as "I" or “me"). However, at a higher level of abstraction, a person's social (or collective) identity can be defined in terms of characteristics that are shared with other in-group members (as "us" or “we”; e.g., "us leadership scholars"; Ellemers, 2012; Reicher, Spears, \& Haslam, 2010).

Building on this distinction, we propose that perceptions of leader authenticity are impacted by the leader's awareness of these different notions of self - that is, of the personal self (i.e., as a unique individual, 'I', in terms of characteristics that make them different from other individuals), as well as of the shared collective self (i.e., as a member of a group membership that is shared with followers, 'we', in terms of the characteristics that define what it means to be a member of that group). In other words, we theorize that self-awareness involves an understanding of both personal and collective identities, each of which will contribute to perceptions of leader authenticity.

\section{Leader Personal Self-Awareness}

Early models of authentic leadership operationalized self-awareness as a process by which individuals reflect on their values, identity, emotions, goals, knowledge, and capabilities (Chan et al., 2015; Illies, Morgeson, \& Nahrgang, 2005). As a result, scholars have emphasized the importance of leaders being able to express their personal values and convictions (e.g., Branson, 2007; Shamir \& Eilam, 2005), for it is through such selfexpression that they are seen to think, feel, and act authentically. To better understand perceptions of authentic leadership, Peus and colleagues (2012) investigated the roles of selfknowledge and self-consistency. They found that follower perceptions were positively influenced by the extent to which leaders were seen to possess self-knowledge, suggesting that self-awareness on the part of leaders may be an important factor in follower perceptions of their authentic leadership. 
Other evidence suggests that self-awareness by leaders matters because it relates to a range of positive outcomes. For instance, leaders who are seen to possess self-awareness have been found to positively influence (a) follower perceptions of leader effectiveness (Butler, Kwantes, \& Boglarsky, 2014), (b) follower satisfaction with their supervisor as well as follower self-leadership (Tekleab, Sims, Yun, Tesluk, \& Cox, 2008), and (c) follower perceptions of their effectiveness (Herbst \& Conradie, 2011; Sur \& Prasad, 2011). In light of previous conceptualizations of authentic leadership and research which highlights the importance of self-awareness, we therefore hypothesize:

H1a. Leaders' personal self-awareness is positively associated with perceptions of their authentic leadership.

H1b. Leaders' personal self-awareness is positively associated with their endorsement as leaders.

\section{Putting Collective Self-Awareness in Authentic Leadership}

Authentic leadership research has placed little emphasis on the way in which collective processes are shaped by leaders' relationship with their group, and it has largely overlooked how individuals respond to leaders as a function of their relationship with the group they lead. To broach these issues, we build on social identity theorizing, which suggests that shared categorization as a member of a collective (e.g., as 'us members of Organization X') has significant implications for political and organizational behavior (Ashforth \& Mael, 1989; Haslam, 2001; Hogg \& Terry, 2002; van Dick, 2001), as well as for leadership and followership (Ellemers, De Gilder, \& Haslam, 2004; Haslam, Reicher, \& Platow, 2011; Hogg, 2001; Hogg, van Knippenberg, \& Rast III, 2012; Steffens et al., 2014; van Dick et al., 2018; van Knippenberg, 2011). At the same time, we also note that the implications of the social identity approach for perceptions of leader authenticity have yet to be explicated. 
One exception, however, is work by Williams and colleagues (2012), which found that congruence between the values of a leader and the group they lead relates to greater follower perceptions of authentic leadership. Another exception is work by Steffens and colleagues' (2016), which found that leaders who champion the interests of an ingroup (rather than their own personal interests or the interests of another group) are seen to be more authentic. Despite these findings, both teams of researchers observed that a great deal of work remains to be done in order to unpack these dynamics.

In this regard, evidence that leaders who prioritize acting on behalf of the group are perceived as more authentic and engender greater support (Steffens et al., 2016) is limited in at least two important ways. First, leaders' ability to champion personal and/or collective interests is likely to be influenced significantly by their self-awareness. That is, in order to be able to purposefully advance their own personal interests and their collective interests, leaders first need to know what drives them as individuals as well as understand what the collective is about (a point that is at the heart of leadership programs inspired by social identity theorizing; see Haslam et al., 2017). Second, this previous research pitted the championing of personal and collective interests against each other. However, a leaders' sensitivity to their personal and collective interests is not necessarily mutually exclusive, but rather awareness of these two forms of self may have simultaneous independent (and possibly synergistic) effects.

In the present work, we address these limitations by exploring the simultaneous effects of personal self-awareness and collective self-awareness on perceptions of authentic leadership and leader endorsement. Drawing on social identity theorizing, which points to the importance of collective identity and the need for leaders to cultivate this (Haslam et al., 2011; Hogg et al., 2012; Reicher, Haslam, \& Hopkins, 2005; Reicher \& Hopkins, 2001), we build upon H1a and H2a to hypothesize that, in addition to leaders' personal self-awareness, 
leaders' understanding of their collective identity (i.e., their collective self-awareness) is an important determinant of both perceptions of their authenticity and endorsement of their leadership. That is:

H2a. Leaders' collective self-awareness is positively associated with perceptions of their authentic leadership.

H2b. Leaders' collective self-awareness is positively associated with their endorsement as leaders.

\section{The Combined Impact of Leader Personal and Collective Self-Awareness}

Beyond testing the distinct effects of personal and collective self-awareness, an additional aim of our research is to explore the potential combined (interactive) effect of these two forms of self-awareness on perceptions of authenticity and leader endorsement. In so doing, we seek to test potential limits (boundary conditions) on the main effects of personal and collective self-awareness, respectively. An important question here is whether these effects are mutually exclusive or independent. Specifically, social identity theorizing (e.g., Turner et al., 2006) suggests that personal self-awareness may in fact be somewhat dependent on collective self-awareness. Indeed, if there is a synergy between these two forms of self-awareness, this would point to important boundary conditions for efforts by leaders to be seen as authentic and thereby win others over.

To understand the potential interactive effects of personal and collective selfawareness, we revert to extensions of self-categorization theory which suggest that the self can be defined at both a personal lower level of abstraction (as "I"), as well as a social/collective higher level of abstraction (as "we"; Turner, 1982). While these levels may be seen as hydraulically inter-related (so that high levels of one imply low levels of the other, as per notions of functional antagonism; Turner et al., 1987), more recent work suggests that the personal and social self are not necessarily independent of each other, and that the 
salience of one aspect of self does not necessarily detract from the salience of another aspect of self (Turner et al., 2006). For example, work with Turkish protestors by Baray, Postmes, and Jetten (2009) found that individuals who strongly identified with the nation also had a stronger sense of personal identity. Similar findings have emerged from the literature on identity fusion, which indicates that individuals do not necessarily have a hydraulic sense of the self as either personal or collective, but rather that these two levels of self can be mutually reinforcing such that individuals are capable of maintaining a sense of both personal self and collective self (Swann, Jetten, Gómez, Whitehouse, \& Bastian, 2012).

In line with research on the interplay between personal and collective self (Baray et al., 2009; Swann et al., 2012), we suggest that the effects of leader awareness of their personal and collective self may be mutually reinforcing. That is, followers are likely to perceive leaders as being true to themselves and be willing to follow them if leaders themselves have an awareness of the characteristics that define them both as an individual and as a member of the group. In the current research we explore these possibilities by examining the extent to which follower perceptions of leader personal and collective selfawareness interact to shape follower perceptions of leader authenticity as well as leader endorsement. More specifically, we hypothesize:

H3a. Leaders' personal self-awareness and collective self-awareness interact to shape perceptions of their authentic leadership, such that leaders who are more aware of their personal self will be seen to display more authentic leadership, particularly when they are also more aware of their collective self.

H3b. Leaders' personal self-awareness and collective self-awareness interact to shape their endorsement as leaders, such that leaders who are more aware of their personal self will be endorsed more strongly, particularly when they are also more aware of their collective self. 


\section{The Present Research}

In line with the foregoing theorizing, in the present research we examine antecedents of authentic leadership by disentangling two aspects of leader self-awareness: personal and collective self-awareness. Across a set of three studies — including an experiment, a field study, and a randomized recall experiment — we examine how leaders' awareness of their personal and collective self impacts perceptions of their authenticity as well leader endorsement. Our primary aim here was to examine the relative contribution of personal and collective self-awareness to authenticity and leader endorsement. In addition, we also sought to explore whether, and to what extent, these two forms of leader self-awareness combine interactively to account for additional variance in perceptions of their authenticity as well their endorsement as leaders. By integrating a social identity perspective with traditional notions of self-awareness, we aim to advance knowledge about how perceptions of leader authenticity are formed. At the same time, we seek to broaden our understanding of how personal and collective self-awareness might combine to promote positive responses to leaders.

To address these issues, our program of research involved a triangulation of methods (as recommended by Cohen, Manion, \& Morrison 2013). This involved conducting studies that used multiple methods so that (a) each study addresses a unique set of questions, while ensuring that (b) the weaknesses of one particular study are compensated for by the strengths of another study.

\section{Study 1}

\section{Method}

Participants and design. We recruited a sample of 529 participants residing in the U.S. via CrowdFlower. Failed attention checks $(n=90)$ resulted in a final sample of 439, as described in more detail below. Participants' mean age was 32.13 years ( $\mathrm{SD}=11.39 ; 6$ did 
not specify), with 222 (50.6\%) identifying as female and five not specifying their gender. Participants were randomly assigned to one of four experimental conditions of a 2 (personal self-awareness: low vs. high) X 2 (collective self-awareness: low vs. high) between-groups design.

Procedure and measures. Participants were invited to take part in a survey entitled "Perceptions of Various CEOs of American Companies". They were presented with a onepage screenshot of an online news article about Tim Cook, CEO of Apple. The article was identical across all conditions with the exception of the experimental manipulations, which were obfuscated such that participants were unaware of the nature of the study and the treatment they received. In all conditions, the article contained a discussion of the company's success, the founder, and the latest mission statement under new leadership. The article also discussed employee perceptions of the CEO's awareness of himself and his company, which were varied to constitute the experimental manipulations.

Specifically, the independent variables were manipulated by varying the degree to which employees perceived the CEO to have (high vs. low levels of) personal self-awareness (referred to in the text with sentences such as "The impact of personal events that shaped his life, the person he has become, and his core personal values"), as well as (high vs. low levels of) awareness of the organization he leads (referred to in the text with sentences such as "The company's history, events, and achievements that have allowed it to thrive, and the group's core values").

These differences between conditions were reinforced by the article's title, a visual graphic, and the text. The title succinctly described the leader's personal self-awareness (low vs. high) and collective self-awareness (low vs. high). For example, the article in the high personal self-awareness / low collective self-awareness condition was entitled "Tim Cook: Deep Understanding of Himself, Little Understanding of Apple" (see Figure 1). The graphic 
embedded in the article showed employee perceptions of their leader's personal and collective self-awareness (a sample of the full manipulation is presented in Figure 2). In this way, we indicated employee perceptions of the leader's personal and collective selfawareness based on prior work suggesting that normative influences (e.g., based on consensual, shared perceptions) are an important determinant of individual thoughts and behaviors (e.g., Cialdini, Reno, \& Kallgren, 1990; Turner, 1991). By referring to shared consensual perceptions of others, our aim was to shape participant perceptions of the leader's personal and collective self-awareness (our variables of interest). Following the visual representation, two concluding sentences summed up the article, again reinforcing the manipulation. Following the random assignment of participants to experimental condition, participants across all conditions responded to the measures as indicated below, before providing demographic information and being debriefed.

Manipulation checks. Participants responded to three items that assessed the extent to which they believed Tim Cook had personal self-awareness $(\alpha=.94)$ : “Tim Cook has a good understanding of how he came to be the individual he is"; "Tim Cook has a clear sense of what his personal morals, values, and beliefs are"; "Tim Cook knows exactly who he is and why he does what he is doing". Three additional items assessed perceptions of his collective self-awareness $(\alpha=.95)$ : "Tim Cook has a clear sense of the core values that guide Apple"; “Tim Cook knows exactly what Apple does, and aims to do"; “Tim Cook has a good understanding of how Apple developed”. Participants responded to all measures on a 7-point scale ranging from 1 (not at all) to 7 (completely).

Authentic leadership. Participants responded to the 14-item Authentic Leadership Inventory (ALI) developed by Neider and Schriesheim (2011). This scale includes four subcomponents: self-awareness $(\alpha=.81$; e.g., "Tim Cook shows that he understands his strengths and weaknesses"); relational transparency ( $\alpha=.79$; e.g., "Tim Cook clearly states 
what he means"); internalized moral perspective ( $\alpha=.84$; e.g., "Tim Cook uses his core beliefs to make decisions"); and balanced processing ( $\alpha=.82$; e.g., "Tim Cook encourages others to voice opposing points of view"). In line with hypotheses that focus on the higherorder construct of authentic leadership (rather than its sub-dimensions) and with conceptualizations of authentic leadership as a higher-order construct in previous research (Gardner et al., 2011), we analyzed the construct as a global factor $(\alpha=.94){ }^{1}$

Leader endorsement. Participants responded to four items assessing leader endorsement adapted from Ullrich, Christ, and van Dick (2009; $\alpha=.95)$ : "Tim Cook is the right person to be Apple's leader"; "Tim Cook is an effective CEO of Apple"; "It is legitimate for Tim Cook to be the CEO of Apple"; "Tim Cook should remain Apple's leader".

\section{Results}

Prior to the main analyses, we screened the data for failed attention checks. A total of 90 participants failed at least one of four attention checks (e.g. "Please select ' 2 ' [this is a control question]"). As recommended by Landers and Behrend (2015), these responses were subsequently excluded from the main analyses.

Main analysis. To test $\mathrm{H} 1, \mathrm{H} 2$, and $\mathrm{H} 3$, we conducted a multivariate analysis of variance (MANOVA) with the manipulations of the two experimental variables (personal self-awareness: low, high) and (collective self-awareness: low, high) as factors on

${ }^{1}$ There is some apparent overlap between the manipulation check items and some of the ALI items that assess self-awareness. However, in contrast to the three ALI items that assess selfawareness in a general sense, the manipulation checks distinguish between two forms of selfawareness: personal and collective. Nevertheless, when the three ALI items assessing self-awareness are excluded, results from the main analysis (in relation to H1-H3) are substantively identical in the present study (as well as in Studies 2 and 3). For the sake of consistency with common conceptualizations and measurements of authentic leadership, all ALI items are included in all subsequent analyses. 
manipulation checks (personal self-awareness, collective self-awareness), authentic leadership, and leader endorsement. Overall sample means, standard deviations, and intercorrelations are presented in Table 1, while conditional means, standard deviations, and inferential statistics (as a function of experimental condition) are presented in Table 2. The MANOVA revealed significant overall (i.e., across all variables) main effects of personal self-awareness (Wilks' lambda $=.55, F(4,432)=86.71, p<.001)$ and collective selfawareness (Wilks' lambda $=.58, F(4,432)=77.01, p<.001)$, but the overall interaction was not significant (Wilks' lambda $=1.00, F(4,432)=0.36, p=.840)$. These results were followed up by simple ANOVAs for each variable as described below.

Manipulation checks. Analysis revealed a significant effect of the experimental manipulation of personal self-awareness on participant perceptions of the leader's personal self-awareness, $F(1,435)=333.44, p<.001$. This indicated that participants perceived the leader to have greater personal self-awareness in the high personal self-awareness condition $(M=5.91 ; S D=0.84)$ than in the low personal self-awareness condition $(M=3.75 ; S D=$ 1.54), Cohen's $d=1.74,95 \%$ Cis $[1.52,1.96]$. Likewise, there was a significant effect of the experimental manipulation of collective self-awareness on participant perceptions of the leader's collective self-awareness $F(1,435)=282.31, p<.001$. This indicated that participants perceived the leader to have greater collective self-awareness in the high collective self-awareness condition $(M=5.95 ; S D=1.04)$ than in the low collective selfawareness condition $(M=3.82 ; S D=1.56)$, Cohen's $d=1.60,95 \%$ Cis $[1.39,1.82]$. In addition, and as shown in Table 2, there was no evidence that perceptions of leader personal self-awareness were affected by the experimental manipulation of collective self-awareness, $F(1,435)=1.12, p=.291$, or of an interactive effect of the two manipulations, $F(1,435)=$ $1.36, p=.244$. Similarly, perceptions of leader collective self-awareness were not affected by the experimental manipulation of personal self-awareness, $F(1,435)=0.70, p=.403$, nor by 
the interaction between manipulations, $F(1,435)=0.04, p=.835$, suggesting that the experimental manipulations were successful and orthogonal to each other.

Authentic leadership. Analysis revealed a significant effect of personal selfawareness on perceptions of leader authenticity, $F(1,435)=97.30, p<.001$. Supporting H1a, participants perceived the leader (Tim Cook) to be more authentic when he displayed high ( $M$ $=5.11 ; S D=0.77)$ rather than low personal self-awareness $(M=4.20 ; S D=1.18)$, Cohen's $d$ $=0.92,95 \%$ CIs $[0.72,1.11]$. Providing support for $\mathrm{H} 2 \mathrm{a}$, the analysis also revealed a significant effect of collective self-awareness on perceptions of leader authenticity, $F(1,435)$ $=25.00, p<.001$. Participants perceived the leader as more authentic when he displayed high $(M=4.88 ; S D=1.07)$ rather than low collective self-awareness $(M=4.42 ; S D=1.08)$, Cohen's $d=0.43,95 \%$ CIs $[0.23,0.62]$. There was no significant interaction between personal and collective self-awareness, $F(1,435)=0.56, p=.454$, thus providing no support for $\mathrm{H} 3 \mathrm{a}$. Results across the four conditions are presented graphically in Figure 3.

Leader endorsement. Supporting H1b, analysis revealed a significant effect of personal self-awareness on leader endorsement, $F(1,435)=7.46, p=.007$. This indicated that participants were more likely to support the leader when he displayed a high $(M=4.99$; $S D=1.49)$ rather than a low degree of personal self-awareness $(M=4.64 ; S D=1.64)$, Cohen's $d=0.23,95 \%$ CIs $[0.04,0.42]$. Furthermore, supporting H2b, there was a significant effect of collective self-awareness, $F(1,435)=118.68, p<.001$. Participants were more likely to support the leader to the extent that he was seen to have high $(M=5.54, S D=1.21)$ rather than low collective self-awareness $(M=4.09 ; S D=1.57)$, Cohen's $d=1.03,95 \% \mathrm{CIs}$ $[0.83,1.23]$. Results again provided no support for $\mathrm{H} 3 \mathrm{~b}$, as the interaction was not significant, $F(1,435)=0.23, p=.629$. Results across the four conditions are presented visually in Figure 4. 


\section{Discussion}

Study 1 sought to provide a causal examination of the extent to which perceptions of a leader's authenticity and endorsement of that leader (in this case, Tim Cook) are influenced by that leader's personal and collective self-awareness. In support of H1a and H1b, participants regarded a leader who was more (vs. less) aware of his personal self as more authentic, and they were more likely to endorse this leader. Furthermore, supporting H2a and $\mathrm{H} 2 \mathrm{~b}$, participants perceived a leader who was more (vs. less) aware of their collective self to be more authentic, and they were more likely to support this leader as well. However, there was no support for $\mathrm{H} 3 \mathrm{a}$ and $\mathrm{H} 3 \mathrm{~b}$, as there was no evidence of an interaction between personal and collective self-awareness on either authentic leadership or leader endorsement.

Overall, these findings provide evidence of the causal impact of leader awareness of both their personal self and collective self on perceptions of leader authenticity as well as leader endorsement. At the same time, the magnitudes of the effects suggest that in accounting for perceptions of authentic leadership, the effect size for personal self-awareness $(d=0.92)$ was more than twice as large as that for collective self-awareness $(d=0.43)$. At the same time, the relative importance of personal and collective self-awareness was reversed when it came to predicting endorsement of leaders. Here, the effect size for personal selfawareness was small $(d=0.23)$ and less than a quarter of the size of that for collective selfawareness $(d=1.03)$.

Despite the fact that the random assignment of participants to experimental condition yields experimental evidence supporting our key hypotheses (H1a, H1b, H2a, H2b) and allows us to infer causality, the inferences we can draw from these findings are limited. In particular, this is because the study examined participants' perceptions of leaders in general by manipulating evaluations of a well-known leader's self-awareness. This means that these findings do not allow us to make inferences about individuals' responses to their own leader. 
To address this shortcoming and assess the impact of leader self-awareness in a natural context, we conducted a second study exploring the influence of personal and collective selfawareness in an applied field setting.

\section{Study 2}

In this second study, we sought to examine whether the findings from Study 1 would replicate in the field by assessing the effects of leader personal and collective self-awareness on authentic leadership and leader endorsement in the context of the 2016 US Presidential election.

\section{Method}

Participants. Five hundred and sixty-four American participants took part in this study. Participants were recruited via a professional recruiting company, Prolific Academic. Participants who failed at least one of the attention checks $(n=39$; e.g., "This is a control question — please select ' 1 ,") and those who indicated that they were not eligible to vote in the next US Federal Election $(n=12)$ were excluded, resulting in final sample of 513. Participant ages ranged from 18 to 73 years $(M=31.64 ; S D=10.77)$, and $215(41.9 \%)$ were female (3 did not specify gender).

Procedure and measures. We assessed participant perceptions of the leadership of the two election front-runners, Hillary Clinton and Donald Trump, about three months before the 2016 US Presidential election. In this way, the study allowed us to examine perceptions of authenticity in the context of a country-wide decision, while also assessing its coinciding effects on the extent to which individuals were willing to support either candidate by endorsing them in their vote in the ballot box.

Participants were invited to take part in a study entitled "Perceptions of Various US Presidential Candidates". They were randomly assigned to assess the leadership of either Hillary Clinton or Donald Trump. Measures were identical to those used in Study 1, and 
assessed on a 7-point scale ranging from 1 (not at all) to 7 (completely). These included: (a) the same items as used in Study 1 measuring personal self-awareness $(\alpha=.89$; e.g., "[The Leader] has a clear sense of what his/her personal morals, values, and beliefs are"), (b) collective self-awareness ( $\alpha=.96$; e.g., "[The Leader $]$ has a good understanding of how America developed"), (c) authentic leadership (14 items, $\alpha=.95$; Neider \& Schriesheim, 2011), and (d) leader endorsement including the four previous items (Ullrich et al., 2009) with the addition of one item assessing voting intentions ("If elections were held tomorrow, I'd vote for [The Leader]"), thus creating a five item scale $(\alpha=.97)$.

\section{Results}

Means, standard deviations, intercorrelations, and internal consistencies are presented in Table 3. Results from the regression analyses are presented in Table 4.

Main analyses. To assess authentic leadership and leader endorsement as a function of leader self-awareness, we ran a series of hierarchical multiple regression analyses with personal and collective self-awareness entered at Step 1, and the interaction term between these two variables at Step 2. For these analyses, perceptions of leader personal and collective self-awareness were standardized (and these were used to compute the interaction term).

Authentic leadership. Supporting H1a, analysis at Step 1 revealed that leader personal self-awareness was positively associated with perceptions of their authentic leadership, $\beta=.29, b=.44,95 \% \mathrm{CIs}[.34, .53], \mathrm{SE}=.05, p<.001$. There was also support for $\mathrm{H} 2 \mathrm{a}$, as leader collective self-awareness was positively associated with greater perceptions of authentic leadership, $\beta=.62, b=.93,95 \% \mathrm{CIs}[.84,1.02], \mathrm{SE}=.05, p<.001$. Adding the interaction term at Step 2 revealed a significant interaction between personal and collective self-awareness, $\beta=.06, b=.09,95 \% \mathrm{CIs}[.01, .17], \mathrm{SE}=.04, p=.041$. The interaction was deconstructed by a series of simple slopes analyses for personal self-awareness at $1 S D$ above and below the sample mean of collective self-awareness (Figure 5). Results showed that 
perceptions of personal self-awareness were significant positively associated with perceptions of authentic leadership at low levels of perceived collective self-awareness, $\beta=.28, b=.41$, $95 \%$ CIs $[.31, .50], \mathrm{SE}=.05, p<.001$. However, consistent with $\mathrm{H} 3 \mathrm{a}$, the relationship between perceptions of leader personal self-awareness and authentic leadership was stronger when the leader was also seen to possess high levels of collective self-awareness, $\beta=.39, b$ $=.58,95 \%$ CIs $[.41, .74], \mathrm{SE}=.08, p<.001$.

Leader endorsement. Results revealed that leader personal self-awareness was not associated with greater leader endorsement, $\beta=.02, b=.03,95 \% \mathrm{CIs}[-.11, .17], \mathrm{SE}=.07, p$ $=.649$, providing no support for H1b. However, supporting $\mathrm{H} 2 \mathrm{~b}$, results yielded a significant positive relationship between leader collective self-awareness and support for that leader, $\beta$ $=.83, b=1.83,95 \%$ CIs $[1.69,1.97], \mathrm{SE}=.07, p<.001$. Furthermore, supporting H3b, Step 2 revealed a significant interaction between personal and collective self-awareness, $\beta=.14, b$ $=.32,95 \% \mathrm{CIs}[.19, .44], \mathrm{SE}=.06, p<.001$. The interaction (Figure 6 ) was followed up by a series of simple slopes analyses. Results indicated that personal self-awareness was not significantly related to leader endorsement at low levels of leaders' collective self-awareness, $\beta=-.03, b=-.07,95 \%$ CIs $[-.21, .07], \mathrm{SE}=.07, p=.339$. However, providing more specific support for $\mathrm{H} 3 \mathrm{~b}$, under conditions of high leader collective self-awareness, there was a significant positive relationship between leader personal self-awareness and endorsement, $\beta$ $=.26, b=.56,95 \% \mathrm{CIs}[.32, .81], \mathrm{SE}=.12, p<.001$. This finding indicates that people were more likely to lend their support to a presidential candidate to the extent that they perceived the candidate to have awareness of their personal self — but only when they also believed the candidate was displaying collective self-awareness of the (national) group.

\section{Discussion}

Study 2 aimed to build on the findings of Study 1 by testing our hypotheses in an applied context. Supporting H1a and replicating the experimental findings of Study 1, 
followers perceived leaders (Hillary Clinton or Donald Trump) to be more authentic when they displayed more (vs. less) awareness of their personal self. However, we found no evidence for H1b, as a leader's personal self-awareness was not (by itself) associated with support for leaders. On the other hand, supporting $\mathrm{H} 2 \mathrm{a}$ and $\mathrm{H} 2 \mathrm{~b}$, and replicating the findings of Study 1, people perceived a leader to be more authentic and were more likely to follow them to the extent that the leader displayed elevated awareness of their collective self (i.e., a deep understanding of the group they intend to lead). In terms of the magnitude of the effects, leader collective self-awareness had a stronger relationship than personal self-awareness with perceptions of authentic leadership. Leader collective self-awareness also had a stronger association than personal self-awareness with people's willingness to follow them.

Finally, consistent with $\mathrm{H} 3 \mathrm{a}$ and $\mathrm{H} 3 \mathrm{~b}$, there was some evidence that the association between leader personal self-awareness and (a) perceptions of authentic leadership, and (b) leader endorsement, were more pronounced when the leader also displayed high levels of collective self-awareness. The interaction was somewhat stronger on leader endorsement than authentic leadership, but in both cases the interaction explained a relatively small amount of additional variance beyond the independent main effects of personal and collective selfawareness.

Again, this study is not without limitations. First, we assessed our independent variables using scales that were collapsed at the construct level, which can introduce some measurement error (compared to other methodological and statistical techniques; e.g., structural equation modelling; Culpepper, 2012). Relatedly, in the present study (unlike in Study 1), we did not manipulate but rather measured naturally varying levels in the variables of interest; the estimates may be influenced by omitted variables, and we cannot infer causality. Nevertheless, Study 2 extends the findings from Study 1 (that had high internal control and allowed for inferences of causality) and increases confidence in our results 
insofar as the pattern is similar when examined in natural contexts in the field. However, it should be noted that Studies 1 and 2 both provide data on responses to well-known leaders and thus do not allow us to generalize our conclusions to other contexts — especially work contexts involving people's responses to their own supervisors. This was a key limitation that we sought to address in our final study.

\section{Study 3}

In our final study, we used a randomized recall experiment to examine whether the effects of personal and collective self-awareness on perceptions of leader authenticity and leader endorsement would generalize to yet another context — namely, individual responses to their own workplace supervisors. In this study, participants were randomly assigned to one of four conditions in which leaders displayed low (vs. high) levels of personal self-awareness, as well as low (vs. high) levels of collective self-awareness.

\section{Method}

Participants. Seven-hundred and fifty-nine participants responded to our survey. Participants were recruited via Prolific Academic. Participants who indicated they had never worked with a supervisor as specified in one of the randomized conditions below $(n=102)^{2}$ and those who failed the attention check $(n=2$; "This is a control question-please select 'Not at all 1"") were excluded, leaving a total of 655 participants in the analysis. Participants ranged in age from 18 to 68 years $(M=37.61 ; S D=10.95)$, and $429(65.5 \%)$ were female.

\footnotetext{
${ }^{2}$ We conducted additional analyses to examine whether drop out (people's ability to match a leader to the description) was influenced by experimental condition. Logistic regression analysis indicated that the main effect of neither personal self-awareness $(\mathrm{B}=-.17, \mathrm{SE}=.28, p=.550)$, collective self-awareness $(\mathrm{B}=-.53, \mathrm{SE}=.30, p=.079$, nor their interaction $(\mathrm{B}=.18, \mathrm{SE}=.43, p=.686)$ affected whether or not people were able to match a leader to the description, providing no evidence of systematic bias in drop out as a function of experimental condition.
} 
Procedure and measures. Participants were invited to participate in a study about "Person Perception". They were informed that they would be asked to reflect on their experiences with a current or previous team leader, supervisor, or manager. They were then randomly assigned to one of four different experimental conditions of a 2 (personal selfawareness: low vs. high) $\times 2$ (collective self-awareness: low vs. high) between-groups design.

At the start of the study, participants were presented with the description of a leader consistent with their assigned condition. As in Study 1, the manipulations varied the extent to which leaders were depicted as having awareness of their personal self (described as understanding themselves, as well as knowing their core values and what the impact of events shaping their personal life has been) and awareness of their collective self (described as understanding their work unit, as well as knowing how it developed and what its core values are). As in Study 1, the descriptions in the four conditions differed in the summary and the detailed sentences about the leader, varying the degree to which the leader had personal and collective self-awareness (by highlighting the leader's deep vs. limited knowledge in the high vs. low self-awareness conditions). Next, they were asked to reflect on the person they worked with who most closely matched the description (e.g., current or previous team leader, supervisor, or manager), and then to write some short text detailing how that person matched the attributes in the description. If participants were unable to identify a leader, then they were funneled out of the study (and then asked to respond to their current supervisor). Finally, participants were asked to indicate the name of the person, which was then displayed throughout the survey.

Participants then responded to identical measures as used in the previous studies, including the manipulation checks assessing (a) personal self-awareness $(\alpha=.90$; e.g., "[Name of person] has a good understanding of how s/he came to be the individual s/he is") and (b) collective self-awareness $(\alpha=.94$; e.g., "[Name of person] has a clear sense of the 
core values that guide this team"), as well as the independent variables of (c) authentic leadership ( $\alpha=.96$; using the Authentic Leadership Inventory from Neider and Schriesheim, 2011; e.g., "[Name of person] shows consistency between his/her beliefs and actions"), and (d) leader endorsement ( $\alpha=.98$; using the measure from Ullrich et al., 2009; e.g., "[Name of person] is the right person to lead this team"). Participants responded to all measures on a 7point scale ranging from 1 (not at all) to 7 (completely).

\section{Results}

Main analysis. Overall means, standard deviations, intercorrelations, and internal consistencies are presented in Table 5, while inferential statistics including condition means (standard deviations) are displayed in Table 6. To analyze results, we conducted a multivariate analysis of variance (MANOVA) with the two experimental variables (personal self-awareness: low vs. high) and (collective self-awareness: low vs. high) as factors on all variables (manipulation checks and dependent variables). Results from the MANOVA revealed a significant overall effect of personal self-awareness (Wilks' lambda $=.49, F(4$, $648)=165.65, p<.001)$, collective self-awareness $($ Wilks' lambda $=.52, F(4,648)=148.38$, $p<.001$ ), but no significant interaction (Wilks' lambda $=.92, F(4,648)=14.25, p<.836$ ). The follow-up simple ANOVAs for each variable are described in detail below.

Manipulation checks. Results indicated a significant effect of the experimental manipulation of personal self-awareness on the manipulation check assessing participants' perceptions of the leader's personal self-awareness $F(1,651)=630.34, p<.001$. More specifically, participants perceived the leader to have greater personal self-awareness in the high $(M=5.95 ; S D=0.88)$ than in the low personal self-awareness condition $(M=3.67 ; S D$ $=1.44)$, Cohen's $d=1.90,95 \%$ CIs $[1.72,2.09]$. In addition, there was a significant effect (albeit smaller in magnitude) of the experimental manipulation of collective self-awareness, $F(1,651)=55.60, p<.001$, indicating that participants perceived the leader in the high 
collective self-awareness condition was more aware of their personal self $(M=5.17 ; S D=$ 1.57) than the leader in the low collective self-awareness condition $(M=4.43 ; S D=1.65)$, Cohen's $d=0.46,95 \%$ CIs $[0.30,0.61]$. The interaction between the experimental factors was not significant, $F(1,651)=1.33, p=.250$.

Analysis of the manipulation check of collective self-awareness revealed a significant effect of the experimental collective self-awareness condition, $F(1,651)=551.14, p<.001$, indicating that participants perceived the leader to be more aware of their team in the high $(M$ $=5.66 ; S D=1.35)$ than in the low collective self-awareness condition $(M=3.09 ; S D=1.58)$, Cohen's $d=1.75,95 \%$ CIs $[1.57,1.93]$. In addition, the experimental manipulation of personal self-awareness had a significant effect of smaller magnitude on the manipulation check of perceived collective self-awareness, $F(1,651)=77.54, p<.001$, indicating that participants perceived the leader to have more awareness of the team in the high $(M=4.92$; $S D=1.87)$ than in the low personal self-awareness condition $(M=3.89 ; S D=1.90)$, Cohen's $d=0.55,95 \%$ CIs $[0.39,0.70]$. The interaction between the two factors also showed a significant (albeit small) effect on perceived collective self-awareness, $F(1,651)=4.06, p$ $=.044$.

Altogether, analysis revealed that the experimental manipulations had the expected effect on their respective manipulation checks, showing that they were successful. However, the manipulations of self-awareness on one level also affected perceptions of self-awareness on the respective other, non-targeted level. Nonetheless, these effects were much smaller than the effect on the targeted level (e.g., the $F$-value for the experimental manipulation of personal self-awareness on the targeted level was 8 times larger than the $F$-value on the nontargeted level [630.34 vs. 77.54]; similarly, the $F$-value for the experimental manipulation of collective self-awareness on the targeted level was 10 times larger than the $F$-value on the non-targeted level [551.14 vs. 55.60]). The interaction between two experimental factors only 
affected perceptions of collective self-awareness (not personal self-awareness), but the effect was even smaller than the main effects. In light of these results, we consider the experimental manipulations to have been effective, but we are also are mindful that cross-over effects (albeit of smaller magnitude) between personal and collective self-awareness may occur, pointing to a level of correlation between the two when using real-world stimuli in natural contexts. This is a point we return to in the General Discussion.

Authentic leadership. Analysis yielded a significant effect of experimental condition of personal self-awareness, $F(1,651)=220.21, p<.001$. Providing support for H1a, participants perceived the leader to be more authentic when that leader had high $(M=4.90$; $S D=1.42)$ rather than low personal self-awareness $(M=3.49 ; S D=1.35)$, Cohen's $d=1.01$, 95\% CIs $[0.85,1.18]$. The experimental condition of collective self-awareness also had a significant effect, $F(1,651)=243.11, p<.001$. Supporting H2a, participants perceived a leader who had high awareness of the collective (their team) to be more authentic $(M=4.91$; $S D=1.43)$ than a leader who had low collective self-awareness $(M=3.45 ; S D=1.31)$, Cohen's $d=1.07,95 \%$ CIs [0.90, 1.23].

Finally, the two-way interaction also had a significant impact on authentic leadership, $F(1,651)=26.92, p<.001$. The interaction was decomposed by means of pairwise comparisons and is displayed in Figure 7. Providing support for H3a, the effect of personal self-awareness was significant in the condition of low collective self-awareness, $F(1,651)=$ 45.532, $p<.001$, but the effect was even larger in the condition of high collective selfawareness, $F(1,651)=205.292, p<.001$. Specifically, when the leader had low collective self-awareness, participants perceived the leader who had high personal self-awareness to be more authentic $(M=3.90 ; S D=1.28)$ than the leader who had low personal self-awareness $(M=3.02 ; S D=1.19)$. However, this effect of personal self-awareness was much more pronounced when the leader also had high collective self-awareness, with participants 
regarding the leader with high personal self-awareness to be much more authentic $(M=5.80$; $S D=0.80)$ than the leader with little personal self-awareness $(M=3.97 ; S D=1.35)$.

Leader endorsement. The experimental condition of personal self-awareness also had a significant effect on leader endorsement, $F(1,651)=158.284, p<.001$. Consistent with H1b, participants supported the leader to a greater extent when that leader had high $(M=$ $4.87 ; S D=2.20)$ rather low personal self-awareness $(M=3.16 ; S D=2.01)$, Cohen's $d=0.81$, $95 \%$ CIs $[0.65,0.97]$. In addition, the manipulation of collective self-awareness was significant, $F(1,651)=401.34, p<.001$. Providing support for $\mathrm{H} 2 \mathrm{a}$, participants supported the leader who had high awareness of collective (team) identity more strongly $(M=5.30 ; S D$ $=1.84)$ than the leader who had low awareness of collective (team) identity $(M=2.67 ; S D=$ 1.88), Cohen's $d=1.41,95 \%$ CIs $[1.24,1.58]$.

Furthermore, the interaction between the experimental factors (displayed in Figure 8) also had a significant impact on leader endorsement, $F(1,651)=19.34, p<.001$, which we decomposed by means of pairwise comparisons. Supporting H3b, personal self-awareness had a significant (positive) impact on leader endorsement in the condition of low collective self-awareness, $F(1,651)=32.91, p<.001$, but this effect was even stronger in the condition of high collective self-awareness, $F(1,651)=147.92, p<.001$. This meant that when leaders had little awareness of collective (team) identity, participants supported those leaders with high personal self-awareness more strongly $(M=3.22 ; S D=2.00)$ than leaders with little personal self-awareness $(M=2.16 ; S D=1.60)$. However, this effect of leader personal selfawareness was much more pronounced when the leader had high awareness of the collective (team) identity. Under these conditions, participants supported a leader with high levels of personal self-awareness significantly more $(M=6.36 ; S D=0.96)$ than a leader with low levels of personal self-awareness $(M=4.17 ; S D=1.88)$. 


\section{Discussion}

Study 3 provided evidence from a randomized recall experiment that replicated the findings from our previous two studies in showing that leader awareness of both their personal self (the characteristics that define them as an individual) and their collective self (the characteristics the define the team they are leading) simultaneously affected the extent to which people regarded that leader as authentic and supported them. Consistent with the patterns of the two previous studies, leader endorsement (to a lesser extent this was the case for perceptions of authentic leadership) was more strongly affected by collective selfawareness than by personal self-awareness. Finally, in line with findings from Study 2, results also provided some evidence that personal self-awareness and collective self-awareness interacted to shape perceptions of authentic leadership as well as leader endorsement. However, here too the interaction effect was weaker than the main effects of personal and collective self-awareness, and explained little additional variance beyond the main effects. We also note that the experimental manipulations were not perfectly orthogonal; however, the unexpected cross-over effects were a fraction of the size of the expected main effects, and so these cross-over effects are unlikely to explain a substantial amount of the variance above and beyond the intended effects of the manipulations.

\section{General Discussion}

Even though there is a rich body of knowledge about the positive consequences of people perceiving leaders to be authentic, research is just beginning to shed light on the factors that shape the degree to which people perceive their leaders as authentic to begin with (Gardner et al., 2011; Peus et al., 2012; Sidani \& Rowe, 2018; Steffens et al., 2016). In the present research, we aimed to address this lacuna by exploring the consequences of leader awareness of their personal and collective self for perceptions of their authenticity as well as for endorsement of them as leaders. 
Across a diverse set of three studies — including an experiment, an applied field study, and a randomized recall experiment — results indicate that people perceived leaders as more authentic to the degree that those leaders possessed awareness of their personal self (i.e., understanding of their own personal values and beliefs; providing support for H1a). Results also indicate (from Study 1 and 3) that leader awareness of their personal self impacted people's willingness to support that leader (H1b), but the magnitude of this effect was weaker than the effect on authentic leadership. Evidence across all three studies further showed that leader collective self-awareness was associated both with people's perceptions of those leaders' authentic leadership (H2a) and their support for those leaders (H2b). Interestingly, the patterning of the magnitude of these collective self-awareness effects was different from the corresponding effects of leader personal self-awareness. Whereas leader personal self-awareness tended to have stronger effects on perceptions of authentic leadership than it did on people's support for leaders, leader collective self-awareness had stronger effects on people's support than on perceptions of leader authenticity.

Studies 2 and 3 also provided evidence that leader personal and collective selfawareness interacted in a way that influenced people's perceptions of those leaders' authenticity and support for them. Here the pattern of results suggested that leaders' elevated awareness of their personal self had a stronger influence on perceptions of authenticity (H3a) and leader endorsement (H3b) to the extent that leaders displayed collective self-awareness. Indeed, in Study 2 it was only when leaders displayed collective self-awareness that personal self-awareness resulted in greater endorsement. Yet across the studies, where it was present, the interaction effect was much smaller than the main effects of personal and collective selfawareness, suggesting that personal and collective self-awareness exert their effects primarily in independent (rather than interactive) ways. 


\section{Implications for Theory and Practice}

The present findings have at least four important practical and theoretical implications for both leadership and followership. First, they expand on a wealth of research that highlights the importance of perceptions of leader authenticity for leaders' capacity to inspire positive individual and organizational outcomes (for reviews, see Banks et al., 2016; Gardner et al., 2011). In addition, results add to a growing body research that has begun to determine factors that give rise to people's perceptions of authentic leadership (Peus et al., 2012;

Steffens et al., 2016; Weisher et al., 2013; Williams et al., 2012; Zheng et al., 2020).

Specifically, they do so by pointing to the influence of leader awareness not only with respect to their personal self, but also with respect to their collective self (see also Ellemers et al., 2004; Hogg et al., 2012; Platow et al., 2015; van Knippenberg, 2011; van Dick et al., 2018). Indeed, findings indicate that both personal and collective self-awareness are important and practically independent factors that shape people's perceptions of leader authenticity.

Second, elaborating on the previous point, findings suggest that the relationship between leader personal self-awareness and perceptions of authenticity can be enhanced by simultaneous collective self-awareness. Previous work by Steffens et al. (2016) found that leaders who responded to the needs of the collective had a more positive impact on follower perceptions of authentic leadership than leaders who acted in accordance with their personal self. However, this previous research was limited because it did not allow for inferences about the combined impact of issues related to personal and collective identity in shaping perceptions of authenticity. To resolve this problem, in the present research we sought to disentangle the respective influences of personal and collective identity by assessing the impact of personal self-awareness and collective self-awareness simultaneously. Our findings lend support to claims that authentic leadership has a collective dimension (see also Banks et al., 2016; Gill \& Caza, 2018). At the same time, our findings contrast with claims that the 
way in which the self is defined has no practical bearing on authentic leadership (Brown, 2015). To the contrary, our results show that leader awareness of (a) what shapes and guides them as an individual, and (b) what shapes and guides the group that they lead, each contributes to perceptions of their authenticity. We find support for this assertion across all three studies when evaluating senior leaders of companies (Study 1), political candidates (Study 2), and organizational supervisors with whom respondents had worked in the past (Study 3).

In this regard, our findings also have wider implications for contemporary conceptualizations of authentic leadership and social identity theorizing around leadership. Previous research has shown that authentic leadership results from leaders being aware of their true self — which is explicitly defined as awareness of the personal self (as "I" or “me”), both in measurement scales (Neider \& Schriesheim, 2011) and in theoretical models (Chan et al., 2005; lies et al., 2005). Although this is consistent with previous research (Gardner et al., 2011), our findings suggest there may be an alternative, complimentary pathway to authentic leadership. By considering the dynamic nature of the self, and the different ways in which it can be defined (Ashforth et al., 2008; Turner, 1982; Turner et al., 1987; Swann et al., 2012), our findings highlight the importance of distinguishing between different forms of self-awareness. This has practical importance because people may perceive a leader who only possesses awareness of their personal identity (and not of shared collective identity) as unworthy of following. Indeed, a resounding lack of awareness of collective identity weighs heavily on people's willingness to follow because without such awareness, it is difficult (if not impossible) for a leader to purposefully champion the needs of the group and its members (Haslam et al., 2017). This means that factors leading to perceptions of authentic leadership (e.g., personal self-awareness) may not always drive people's support for leaders. Specifically, as much as leaders need to show awareness of both their personal and 
collective self to be seen as authentic, when it comes to inspiring followership, the impact of collective self-awareness appears to be more pronounced.

The present work further contributes to the literature on social identity and leadership by highlighting the importance of leaders 'tuning in' to collective interests in order to secure support (Haslam et al., 2001; Haslam \& Platow, 2001; Steffens et al., 2016; van Knippenberg \& van Knippenberg, 2005). Yet, leaders need first to have awareness of collective concerns and interests before they can be in a position to advance those interests. At the same time, it is worth noting that personal self-awareness had an additional independent effect on leader endorsement (even though this was significantly smaller than that for collective selfawareness). While questions around personal identity have not been a major focus in this growing literature (Epitropaki et al., 2017; van Dick et al., 2018), the present findings suggest that there are other additional influences deriving from awareness not only of the group in question but also of other entities (e.g., individual group members) that may explain people's willingness to support a leader.

Finally, the current work has important implications for the training, development, and practice of authentic leadership in informing the ways in which leaders can shape perceptions of authenticity and simultaneously encourage followership. In the first instance, our findings point to the importance of leaders developing an awareness and understanding of their personal morals, values, and beliefs for fostering others' perceptions of their authenticity. However, they also point to the need for leaders to have a clear understanding of the collective (i.e., the group or organization) that they lead (e.g., of its history, values, interests, and goals), not only to foster perceptions of their authenticity but also to secure support. In this way, the present work provides leaders with concrete and expanded ways to think both about what it means to be authentic and what drives others' perceptions of their authenticity. 


\section{Limitations, Critical Reflections, and Directions for Future Research}

We acknowledge that the present research is not without its limitations. More generally, this program of work was guided by an interest in methodological triangulation such that the weaknesses of one study would be addressed by the strengths of another. This meant, for example, that in Study 2 we did not manipulate the variables of interest, and so the independent variables are not exogenous and the inferences we can derive from this study are limited. Specifically, we cannot infer causality because the estimates that we obtained for the relationships of interest are likely to be biased. Nevertheless, the experimental studies that used random assignment to experimental conditions sought to correct for this.

We also recognize that in some experimental studies, manipulations and manipulation checks that appear prior to dependent variables can bias the results by creating demand effects (see Lonati, Quiroga, Zehnder, \& Antonakis, 2018). In the present set of studies, however, demand effects arising from the manipulations themselves are unlikely to play a significant role. This is because experimental manipulations were designed in such a way that they did not make reference to the valence of particular characteristics, but rather varied the extent and depth of knowledge about (two) different leader aspects (i.e., personal and collective self-awareness), knowledge that is no more or less positive (or negative) than knowledge about any other topic. Consistent with this assertion, there was also no evidence of "poison medicine effects", as results show that in the conditions in which levels of a manipulated variable were low, perceptions of authentic leadership and leader endorsement were neutral (i.e., around the mid-point of the scale). We also note that in some contexts, the use of manipulation checks that appear prior to dependent variables can influence responses (by intensifying or weakening responses; Bless \& Bruger, 2016; Lonati et al., 2018). Yet this is unlikely to have occurred in the present set of studies because (a) the manipulations used here were immersive for participants, (b) participants were not aware that there were any 
other conditions (nor what variables varied across conditions), nor were they aware of our hypotheses. Nevertheless, we cannot determine the influence of the manipulation checks.

In this context it is also interesting to observe that until now authentic leadership has largely been treated as an intrinsic leader attribute in both theory and practice (rather than as an inference that others make). As a result, research has often started with people's perceptions of a given leader's authenticity (as we did in Study 2). Our findings, though, suggest that there is value in 'panning back' to delve further into what being self-aware and being 'authentic' means (see also Alvesson \& Einola, 2019; Eurich, 2018), while also reflecting on collective dimensions of self that shape people's perceptions of leader authenticity (e.g., Williams et al., 2012; Zheng et al., 2020). In particular, there would be value in future work using experimental and intervention research to examine how perceivers' own self-awareness shapes perceptions of authentic leadership. Moreover, while the current work examined self-awareness of a form that has been at the center of authentic leadership theory to date, future work might explore whether and how (personal and collective) self-awareness also shapes perceptions of other forms of leadership, as well as other additional outcomes (e.g., openness to the leader's suggestions).

In this regard, it is also apparent that the present work raises broader questions about the nature of self and the relevance of this for research on authenticity. In particular, we note that, as we found in Study 3, the effects of personal self-awareness and collective selfawareness may overlap to varying degrees, and this raises broader questions about the relationship between these two distinct constructs (e.g., as discussed by Turner et al., 2006). In this work, we treated 'personal self' and 'collective self' as two alternative (but potentially related) independent variables. This makes sense for the purposes of a controlled laboratory experiment. However, in our view it is important to reflect on the possibility that, in many (perhaps most) contexts, people do not have access to information about whether or not their 
leader is aware of their 'personal self'. A related question is whether we should conceive of 'the true self' as inherently good or noble (see also Alvesson \& Einola, 2019). In the search for one's true noble self that is commonly encouraged by authenticity researchers, what is often overlooked is the possibility that, at core, a leader may be selfish, vain and narcissistic. It would therefore make sense for future research to examine (experimentally or otherwise) how alternative (deviant) forms of authenticity influence perceived leader authenticity and willingness to follow.

The above reflections may seem rather academic. However, in our view it is important to acknowledge these deeper conceptual challenges, not least because this helps us appreciate (a) the limitations of research anchored in the belief in a stable and knowable 'personal self', and (b) the importance of research into collective self and collective sense-making as processes shaping perceived leader authenticity. After all, we can only speculate about a leader's self and truthfulness to that self, but as the present research demonstrates, what can be established in more or less objective ways is whether a leader is perceived to be authentic. In this regard, there would be value in future work to explore the contexts in which leader authenticity may have detrimental effects on people's willingness to support them.

Finally, two of the three studies in the present research focused on well-known leaders and so our results cannot convincingly be generalized to other contexts in which individuals have different relationships and levels of familiarity with leaders. We would also highlight that the participants in all our studies were members of the general public recruited via professional sampling companies. Even though this allowed us to study large samples, there would be value in future work exploring the present issues in other samples (e.g., within a particular organization). We would also point out that our studies focused on only one collective identity (i.e., the group that leaders had formal responsibility for). However, previous work suggests that the self is more dynamic and expansive than these 
operationalizations (Ellemers, 2012; Reicher et al., 2010; Turner, 1991; Turner et al., 1987). For example, leaders are likely to be members of more than just one group and are thus capable of displaying awareness of many different collective identities (which may or may not have similar core values, missions, and histories; Hogg, van Knippenberg, \& Rast III, 2012b; Steffens, Peters, Haslam, \& Platow, 2019). Future research might investigate the consequences of leaders being seen to have multiple group memberships — perhaps displaying awareness of some, none, or all other self-categorizations — and assess how this influences perceptions of their leadership and, through this, the support they engender.

\section{Conclusion}

The present research expands our knowledge of factors that influence perceptions of authentic leadership — perceptions that previous research has shown to have a range of positive consequences for followers and for organizations (Gardner et al., 2011). Our findings draw attention to the importance of the collective for authentic leadership in showing that beliefs about leader authenticity are shaped by others perceiving them as having an awareness not only of their personal identity (as "I" or "me"), but also of their collective identity (as "we" or "us"). Results further indicate that personal self-awareness and collective selfawareness both also have a significant bearing on people's willingness to support leaders. Here, though, collective self-awareness appears to have a stronger impact than personal selfawareness. So, while leader displays of personal self-awareness shape beliefs about their authenticity, it is their collective self-awareness that determines not just whether they are seen to be authentic, but also whether they are seen to be worth following. 


\section{References}

Alvesson, M., \& Einola, K. (2019). Warning for excessive positivity: Authentic leadership and other traps in leadership studies. The Leadership Quarterly, 30(4), 383-395.

Ashforth, B. E., \& Mael, F. (1989). Social identity theory and the organization. Academy of Management Review, 14(1), 20-39.

Ashforth, B. E., Harrison, S. H., \& Corley, K. G. (2008). Identification in organizations: An examination of four fundamental questions. Journal of Management, 34(3), 325-374.

Banks, G. C., McCauley, K. D., Gardner, W. L., \& Guler, C. E. (2016). A meta-analytic review of authentic and transformational leadership: A test for redundancy. The Leadership Quarterly, 27(4), 634-652.

Baray, G., Postmes, T., \& Jetten, J. (2009). When I equals we: Exploring the relation between social and personal identity of extreme right-wing political party members. British Journal of Social Psychology, 48(4), 625-647.

Bless, H., \& Burger, A. M. (2016). A closer look at social psychologists' silver bullet: Inevitable and evitable side effects of the experimental approach. Perspectives on Psychological Science, 11(2), 296-308.

Branson, C. (2007). Effects of structured self-reflection on the development of authentic leadership practices among Queensland primary school principals. Educational Management Administration \& Leadership, 35(2), 225-246.

Brown, A. D. (2015). Identities and identity work in organizations. International Journal of Management Reviews, 17(1), 20-40.

Butler, A. M., Kwantes, C. T., \& Boglarsky, C. A. (2014). The effects of self-awareness on perceptions of leadership effectiveness in the hospitality industry: A cross cultural investigation. International Journal of Intercultural Relations, 40, 87-98. 
Černe, M., Dimovski, V., Marič, M., Penger, S., \& Škerlavaj, M. (2014). Congruence of leader self-perceptions and follower perceptions of authentic leadership: Understanding what authentic leadership is and how it enhances employees' job satisfaction. Australian Journal of Management, 39(3), 453-471.

Chan, A., Hannah, S.T. and Gardner, W.L. (2005), "Veritable authentic leadership: emergence, functioning, and impacts”, in W. Gardner, B. J. Avolio, and F.O. Walumbwa (Eds), Authentic Leadership Theory and Practice: Origins, Effects and Development, Elsevier, San Francisco, CA, pp. 3-41.

Cialdini, R. B., Reno, R. R., \& Kallgren, C. A. (1990). A focus theory of normative conduct: recycling the concept of norms to reduce littering in public places. Journal of Personality and Social Psychology, 58, 1015-1026.

Clapp-Smith, R., Vogelgesang, G. R., \& Avey, J. B. (2009). Authentic leadership and positive psychological capital the mediating role of trust at the group level of analysis. Journal of Leadership \& Organizational Studies, 15(3), 227-240.

Cohen, L. Manion, L. \& Morrison, K. (2013). Research Methods in Education ( $7^{\text {th }}$ ed.). New York: Routledge.

Cooper, C. D., Scandura, T. A., \& Schriesheim, C. A. (2005). Looking forward but learning from our past: Potential challenges to developing authentic leadership theory and authentic leaders. The Leadership Quarterly, 16(3), 475-493.

Culpepper, S. A. (2012). Evaluating EIV, OLS, and SEM estimators of group slope differences in the presence of measurement error: The single-indicator case. Applied Psychological Measurement, 36(5), 349-374.

Ellemers, N. (2012). The group self. Science, 336(6083), 848-852. 
Ellemers, N., De Gilder, D., \& Haslam, S. A. (2004). Motivating individuals and groups at work: A social identity perspective on leadership and group performance. Academy of Management Review, 29(3), 459-478.

Eurich, T. (2018). What self-awareness really is (and how to cultivate it). Harvard Business Review. Retrieved 1 November 2020 from https://hbr.org/2018/01/what-selfawareness-really-is-and-how-to-cultivate-it

Fields, D. L. (2007). Determinants of follower perceptions of a leader's authenticity and integrity. European Management Journal, 25(3), 195-206.

George, W., \& Sims, P. (2007). True north: Discover your authentic leadership. San Francisco: Jossey-Bass.

Gardner, W. L., Cogliser, C. C., Davis, K. M., \& Dickens, M. P. (2011). Authentic leadership: A review of the literature and research agenda. The Leadership Quarterly, 22(6), 1120-1145.

George, B. (2010). True north: Discover your authentic leadership (Vol. 143): John Wiley \& Sons.

Giallonardo, L. M., Wong, C. A., \& Iwasiw, C. L. (2010). Authentic leadership of preceptors: predictor of new graduate nurses' work engagement and job satisfaction. Journal of Nursing Management, 18(8), 993-1003.

Gill, C., \& Caza, A. (2018). An investigation of authentic leadership's individual and group influences on follower responses. Journal of Management, 44(2), 530-554.

Haslam, S. A. (2001). Psychology in organizations: The social identity approach. London: Sage.

Haslam, S. A., \& Platow, M. J. (2001). The link between leadership and followership: How affirming social identity translates vision into action. Personality and Social Psychology Bulletin, 27(11), 1469-1479. 
Haslam, S. A., Platow, M. J., Turner, J. C., Reynolds, K. J., McGarty, C., Oakes, P. J., . . Veenstra, K. (2001). Social identity and the romance of leadership: The importance of being seen to be 'doing it for us'. Group Processes \& Intergroup Relations, 4(3), 191205.

Haslam, S. A., Reicher, S. D., \& Platow, M. J. (2011). The new psychology of leadership: Identity, influence and power: London \& New York: Psychology Press.

Haslam, S. A., Steffens, N. K., Peters, K., Boyce, R. A., Mallett, C. J., \& Fransen, K. (2017). A social identity approach to leadership development: The 5R program. Journal of Personnel Psychology, 16, 113-124.

Herbst, T. H., \& Conradie, P. D. (2011). Leadership effectiveness in Higher Education: Managerial self-perceptions versus perceptions of others. SA Journal of Industrial Psychology, 37(1), 1-14.

Hmieleski, K. M., Cole, M. S., \& Baron, R. A. (2012). Shared authentic leadership and new venture performance. Journal of Management, 38(5), 1476-1499.

Hogg, M. A. (2001). A social identity theory of leadership. Personality and Social Psychology Review, 5(3), 184-200.

Hogg, M. A., \& Terry, D. J. (2002). Social identity processes in organizational contexts: New York: Psychology Press.

Hogg, M. A., van Knippenberg, D., \& Rast III, D. E. (2012). The social identity theory of leadership: Theoretical origins, research findings, and conceptual developments. European Review of Social Psychology, 23(1), 258-304.

Hogg, M. A., van Knippenberg, D., \& Rast III, D. E. (2012b). Intergroup leadership in organizations: Leading across group and organizational boundaries. Academy of Management Review, 37(2), 232-255. 
Ilies, R., Morgeson, F. P., \& Nahrgang, J. D. (2005). Authentic leadership and eudaemonic well-being: Understanding leader-follower outcomes. The Leadership Quarterly, 16(3), 373-394.

Landers, R. N., \& Behrend, T. S. (2015). An inconvenient truth: Arbitrary distinctions between organizational, Mechanical Turk, and other convenience samples. Industrial and Organizational Psychology, 8(02), 142-164.

Laschinger, H. K. S., \& Fida, R. (2014). New nurses burnout and workplace wellbeing: The influence of authentic leadership and psychological capital. Burnout Research, 1(1), $19-28$.

Leroy, H., Anseel, F., Gardner, W. L., \& Sels, L. (2015). Authentic Leadership, Authentic Followership, Basic Need Satisfaction, and Work Role Performance A Cross-Level Study. Journal of Management, 41(6), 1677-1697.

Lonati, S., Quiroga, B. F., Zehnder, C., \& Antonakis, J. (2018). On doing relevant and rigorous experiments: Review and recommendations. Journal of Operations Management, 64, 19-40.

Neider, L. L., \& Schriesheim, C. A. (2011). The Authentic Leadership Inventory (ALI): Development and empirical tests. The Leadership Quarterly, 22(6), 1146-1164.

Parke, H. W., \& Wormell, D. E. W. (1956). The Delphic Oracle (Vol. 1): Blackwell.

Peus, C., Wesche, J. S., Streicher, B., Braun, S., \& Frey, D. (2012). Authentic leadership: An empirical test of its antecedents, consequences, and mediating mechanisms. Journal of Business Ethics, 107(3), 331-348.

Platow, M. J., Haslam, S. A., Reicher, S. D., \& Steffens, N. K. (2015). There is no leadership if no-one follows: Why leadership is necessarily a group process. International Coaching Psychology Review, 10(1), 20-37. 
Rego, A., Sousa, F., Marques, C., \& e Cunha, M. P. (2012). Authentic leadership promoting employees' psychological capital and creativity. Journal of Business Research, 65(3), 429-437.

Reicher, S., Haslam, S. A., \& Hopkins, N. (2005). Social identity and the dynamics of leadership: Leaders and followers as collaborative agents in the transformation of social reality. The Leadership Quarterly, 16(4), 547-568.

Reicher, S. D., \& Hopkins, N. (2001). Self and nation: Categorization, contestation, and mobilisation. London: Sage.

Reicher, S. D., Spears, R., \& Haslam, S. A. (2010). The social identity approach in social psychology. In M. S. Wetherell \& C. T. Mohanty (Eds.), Sage Identities Handbook (pp. 45-62). London: Sage.

Shamir, B., \& Eilam, G. (2005). "What's your story?” A life-stories approach to authentic leadership development. The Leadership Quarterly, 16(3), 395-417.

Steffens, N. K., Haslam, S. A., Reicher, S. D., Platow, M. J., Fransen, K., Yang, J., . . Boen, F. (2014). Leadership as social identity management: Introducing the Identity Leadership Inventory (ILI) to assess and validate a four-dimensional model. The Leadership Quarterly, 25(5), 1001-1024.

Steffens, N. K., Mols, F., Haslam, S. A., \& Okimoto, T. G. (2016). True to what We stand for: Championing collective interests as a path to authentic leadership. The Leadership Quarterly, 27(5), 726-744.

Steffens, N. K., Peters, K., Haslam, S. A., \& Platow, M. J. (2019). One of us... and us... and us: Evidence that leaders' multiple identity prototypicality (LMIP) is related to their perceived effectiveness. Comprehensive Results in Social Psychology, 1-24.

Sur, V., \& Prasad, V. (2011). Relationship Between Self-Awareness and Transformational Leadership: A Study in IT Industry. IUP Journal of Organizational Behavior, 10(1). 
Swann, W. B., Jr., Jetten, J., Gómez, Á., Whitehouse, H., \& Bastian, B. (2012). When group membership gets personal: A theory of identity fusion. Psychological Review, 119(3), $441-456$.

Tekleab, A. G., Sims, H. P., Yun, S., Tesluk, P. E., \& Cox, J. (2008). Are we on the same page? Effects of self-awareness of empowering and transformational leadership. Journal of Leadership \& Organizational Studies, 14(3), 185-201.

Turner, J. C. (1982). Towards a redefinition of the social group. In H. Tajfel (Ed.), Social Identity and Intergroup Relations (pp. 15-40). Cambridge: Cambridge University Press.

Turner, J. C. (1991). Social influence. Milton Keynes: Open University Press.

Turner, J. C., Hogg, M. A., Oakes, P. J., Reicher, S. D., \& Wetherell, M. S. (1987). Rediscovering the social group: A self-categorization theory. Cambridge, MA, US: Basil Blackwell.

Turner, J. C., Reynolds, K. J., Haslam, S. A. \& Veenstra, K. (2006). Reconceptualizing personality: Producing individuality through defining the personal self. In T. Postmes \& J. Jetten (Eds.), Individuality and the group: Advances in social identity (pp.11-36). Sage.

Ullrich, J., Christ, O., \& van Dick, R. (2009). Substitutes for procedural fairness: prototypical leaders are endorsed whether they are fair or not. Journal of Applied Psychology, 94(1), 235.

van Dick, R. (2001). Identification in organizational contexts: Linking theory and research from social and organizational psychology. International Journal of Management Reviews, 3(4), 265-283.

van Dick, R., Lemoine, J. E., Steffens, N. K., Kerschreiter, R., Akfirat, S. A., Avanzi, L., ... \& González, R. (2018). Identity leadership going global: Validation of the Identity 
Leadership Inventory across 20 countries. Journal of Occupational and Organizational Psychology, 91(4), 697-728.

van Knippenberg, D. (2011). Embodying who we are: Leader group prototypicality and leadership effectiveness. The Leadership Quarterly, 22(6), 1078-1091.

van Knippenberg, B., \& van Knippenberg, D. (2005). Leader Self-Sacrifice and Leadership Effectiveness: The Moderating Role of Leader Prototypicality. Journal of Applied Psychology, 90(1), 25-37

Vick, K., \& Shuster, S. (2015, December 21). TIME person of the year 2015: Angela Merkel. Retrieved 11 November 2019 from http://time.com/time-person-of-the-year-2015angela-merkel/

Wang, H., Sui, Y., Luthans, F., Wang, D., \& Wu, Y. (2014). Impact of authentic leadership on performance: Role of followers' positive psychological capital and relational processes. Journal of Organizational Behavior, 35(1), 5-21.

Weischer, A. E., Weibler, J., \& Petersen, M. (2013). "To thine own self be true": The effects of enactment and life storytelling on perceived leader authenticity. The Leadership Quarterly, 24(4), 477-495.

Williams, E. A., Pillai, R., Deptula, B., \& Lowe, K. B. (2012). The effects of crisis, cynicism about change, and value congruence on perceptions of authentic leadership and attributed charisma in the 2008 presidential election. The Leadership Quarterly, 23(3), 324-341.

Wong, C. A., \& Cummings, G. G. (2009). The influence of authentic leadership behaviors on trust and work outcomes of health care staff. Journal of Leadership Studies, 3(2), 623.

Zheng, M. X., Yuan, Y., van Dijke, M., De Cremer, D., \& Van Hiel, A. (2020). The interactive effect of a leader's sense of uniqueness and sense of belongingness on 
followers' perceptions of leader authenticity. Journal of Business Ethics, 164(3), 515533. 


\section{Tables and Figures}

Table 1. Study 1: Means, standard deviations, internal consistencies, and intercorrelations between variables.

\begin{tabular}{lccccccccc}
\hline Variable & Mean & SD & 1 & 2 & 3 & 4 & 5 & 6 & 7 \\
\hline \multicolumn{1}{c}{ Experimental Manipulations } & & & & & & & & & \\
1. Experimental Condition PSA ${ }^{\mathrm{a}}$ & 0.49 & 0.50 & - & & & & & & \\
2. Experimental Condition CSA & b & 0.50 & 0.50 & -.01 & - & & & & \\
3. Interaction PSA * CSA & 0.24 & 0.43 & .57 & .57 & - & & & & \\
$\quad$ Manipulation Checks & & & & & & & & & \\
4. Personal Self-awareness & 4.82 & 1.65 & .66 & -.04 & .38 & $(.94)$ & & & \\
5. Collective Self-awareness & 4.88 & 1.70 & .03 & .63 & .38 & .14 & $(.95)$ & & \\
$\quad$ Dependent Measures & & & & & & & & & \\
6. Authentic Leadership & 4.65 & 1.10 & .42 & .21 & .38 & .72 & .47 & $(.94)$ \\
7. Leader Endorsement & 4.81 & 1.58 & .11 & .46 & .34 & .27 & .76 & .59 & $(.95)$ \\
\hline
\end{tabular}

Note. $N=439 ;$ a Experimental Condition PSA = Experimental Condition Personal Self-

Awareness dummy coded as 0 (low personal self-awareness) and 1 (high personal selfawareness); ${ }^{b}$ Experimental Condition CSA = Experimental Condition Collective SelfAwareness dummy coded as 0 (low collective self-awareness) and 1 (high collective selfawareness); ' Interaction PSA * CSA = Interaction between experimental conditions PSA and CSA; All measures were assessed on 7-point scales ranging from 1 (not at all) to 7 (completely).

$r \mathrm{~s} \geq|.10|$ statistically significant at $p<.05, r \mathrm{~s} \geq|.16|$ statistically significant at $p<.001$. ${ }^{*} p<0.05 ;{ }^{* *} p<0.001$. Cronbach's alpha for each variable is reported in parentheses $(\alpha)$. 
Table 2. Study 1: Means (standard deviations in parenthesis), and inferential statistics for authentic leadership and leader endorsement as a function of experimental condition.

\begin{tabular}{|c|c|c|c|c|c|c|c|}
\hline \multirow[b]{3}{*}{ Variable } & \multicolumn{4}{|c|}{ Means (SDs) in Experimental Conditions } & \multicolumn{3}{|c|}{ Inferential Statistics for Experimental Conditions } \\
\hline & \multicolumn{2}{|c|}{ Low PSA $(N=222)$} & \multicolumn{2}{|c|}{ High PSA $(N=217)$} & \multirow{2}{*}{$\begin{array}{c}\text { PSA } \\
F(1,435)\end{array}$} & \multirow{2}{*}{$\begin{array}{c}\text { CSA } \\
F(1,435)\end{array}$} & \multirow{2}{*}{$\begin{array}{l}\text { Interaction } \\
F(1,435)\end{array}$} \\
\hline & $\begin{array}{c}\text { Low CSA } \\
(N=111)\end{array}$ & $\begin{array}{c}\text { High CSA } \\
(N=111)\end{array}$ & $\begin{array}{c}\text { Low CSA } \\
(N=110)\end{array}$ & $\begin{array}{c}\text { High CSA } \\
(N=107)\end{array}$ & & & \\
\hline Manipulation Check: PSA & $3.88(1.40)$ & $3.62(1.66)$ & $5.91(0.93)$ & $5.92(0.75)$ & $333.44^{* *}$ & 1.12 & 1.36 \\
\hline Manipulation Check: CSA & $3.78(1.56)$ & $5.89(1.20)$ & $3.86(1.57)$ & $6.02(0.84)$ & 0.70 & $282.31^{* *}$ & 0.04 \\
\hline Authentic Leadership & $4.00(1.20)$ & $4.40(1.13)$ & $4.85(0.73)$ & $5.38(0.71)$ & $97.33^{* *}$ & $25.00^{* * *}$ & 0.56 \\
\hline Leader Endorsement & $3.94(1.61)$ & $5.33(1.36)$ & $4.24(1.53)$ & $5.76(0.99)$ & $7.46^{*}$ & $118.68^{* *}$ & 0.23 \\
\hline
\end{tabular}

Note. PSA = Personal Self-Awareness, CSA = Collective Self-Awareness. All measures were assessed on 7-point scales ranging from 1 (not at all) to 7 (completely). ${ }^{*} p<0.05 ;{ }^{* *} p<0.001$. 
Table 3. Study 2: Means, standard deviations, internal consistencies, and intercorrelations between variables.

\begin{tabular}{llllllll}
\hline Variable & Mean & SD & 1 & 2 & 3 & 4 & 5 \\
\hline 1. Personal Self-Awareness (PSA) & 4.66 & 1.74 & $(.89)$ & & & & \\
2. Collective Self-Awareness (CSA) & 3.66 & 1.97 & .67 & $(.96)$ & & & \\
3. PSA * CSA & 0.67 & 0.98 & -.36 & .04 & - & & \\
4. Authentic Leadership & 3.60 & 1.49 & .71 & .82 & -.04 & $(.95)$ & \\
5. Leader Endorsement & 3.11 & 2.20 & .57 & .84 & .13 & .82 & $(.97)$ \\
\hline
\end{tabular}

Note. $N=513$; All measures were assessed on 7-point scales ranging from 1 (not at all) to 7 (completely). ${ }^{a}$ Personal self-awareness and collective self-awareness were Z-standardized prior to calculating interaction term; Cronbach's alpha for each variable is reported in parentheses $(\alpha)$.

$r \mathrm{~s} \geq|.09|$ statistically significant at $p<.05, r \mathrm{~s} \geq|.15|$ statistically significant at $p<.001$. All correlations, $p<0.001$. 
Table 4. Study 2: Hierarchical regression analyses for authentic leadership and leader endorsement as a function of leader personal and collective self-awareness.

\begin{tabular}{|c|c|c|c|c|c|c|c|c|}
\hline \multirow{2}{*}{$\begin{array}{c}\text { Variable } \\
\text { Step } 1\end{array}$} & \multicolumn{4}{|c|}{ Authentic Leadership } & \multicolumn{4}{|c|}{ Leader Endorsement } \\
\hline & $\beta$ & $b$ [95\%CIs] & $S E$ & $t$ & $\beta$ & $b[95 \% \mathrm{CIs}]$ & $S E$ & $t$ \\
\hline Personal Self-Awareness & .29 & $.44[.34, .53]$ & .05 & $9.27^{* *}$ & .02 & $.03[-.11, .17]$ & .07 & 0.46 \\
\hline Collective Self-Awareness & .62 & $.93[.84,1.02]$ & .05 & $19.73^{* *}$ & .83 & $1.83[1.69,1.97]$ & .07 & $25.68^{* *}$ \\
\hline \multicolumn{9}{|l|}{ Model } \\
\hline$R^{2}$ & $.720^{* *}$ & & & & $.707^{* *}$ & & & \\
\hline \multicolumn{9}{|l|}{ Step 2} \\
\hline Personal Self-Awareness & .33 & $.49[.39, .60]$ & .06 & $9.03^{* *}$ & .11 & $.25[.09, .41]$ & .08 & $3.04^{*}$ \\
\hline Collective Self-Awareness & .60 & $.89[.79, .99]$ & .05 & $17.31^{* *}$ & .76 & $1.67[1.52,1.82]$ & .08 & $22.05^{* *}$ \\
\hline $\begin{array}{l}\text { Personal Self-Awareness X } \\
\text { Collective Self-Awareness }\end{array}$ & .06 & $.09[.01, .17]$ & .04 & $2.05^{*}$ & .14 & $.32[.19, .44]$ & .06 & $5.12^{* *}$ \\
\hline \multicolumn{9}{|l|}{ Model } \\
\hline$\Delta R^{2}$ & $.002^{*}$ & & & & $.014^{*}$ & & & \\
\hline$R^{2}$ & $.722^{* *}$ & & & & $.721^{* *}$ & & & \\
\hline
\end{tabular}

Note. CIs = Confidence Intervals; PSA and CSA were centred prior to inclusion in the analysis and prior to calculating interaction term; All measures were assessed on 7-point scales ranging from 1 (not at all) to 7 (completely). ${ }^{*} p<.05,{ }^{* *} p<.001$. 
Table 5. Study 3: Means, standard deviations, internal consistencies, and intercorrelations between variables.

\begin{tabular}{llllllllll}
\hline Variable & Mean & SD & 1 & 2 & 3 & 4 & 5 & 6 & 7 \\
\hline \multicolumn{1}{c}{ Experimental Manipulations } & & & & & & & & & \\
1. Experimental Condition PSA & 0.50 & 0.50 & - & & & & & & \\
2. Experimental Condition CSA & 0.51 & 0.50 & .03 & - & & & & & \\
3. Interaction PSA * CSA c & 0.26 & 0.44 & .60 & .58 & - & & & & \\
$\quad$ Manipulation Checks & & & & & & & & & \\
4. Personal Self-awareness & 4.81 & 1.65 & $.69^{* *}$ & $.22^{* *}$ & .51 & $(.90)$ & & & \\
5. Collective Self-awareness & 4.40 & 1.95 & $.27^{* *}$ & $.66^{* *}$ & .56 & $.55^{*}$ & $(.94)$ & & \\
$\quad$ Dependent Measures & & & & & & & & & \\
6. Authentic Leadership & 4.20 & 1.55 & $.45^{* *}$ & $.47^{* *}$ & .62 & $.70^{* *}$ & $.79^{* *}$ & $(.96)$ \\
7. Leader Endorsement & 4.01 & 2.28 & $.38^{* *}$ & $.58^{* *}$ & .62 & $.61^{* *}$ & $.86^{* *}$ & $.88^{* *}$ & $(.98)$ \\
\hline
\end{tabular}

Note. $N=655$; ${ }^{\text {a }}$ Experimental Condition PSA = Experimental Condition Personal Self-

Awareness dummy coded as 0 (low personal self-awareness) and 1 (high personal selfawareness); ${ }^{b}$ Experimental Condition CSA $=$ Experimental Condition Collective SelfAwareness dummy coded as 0 (low collective self-awareness) and 1 (high collective selfawareness); ${ }^{\mathrm{C}}$ Interaction PSA $* \mathrm{CSA}=$ Interaction between experimental conditions PSA and CSA; All measures were assessed on 7-point scales ranging from 1 (not at all) to 7 (completely). Cronbach's alpha for each variable is reported in parentheses $(\alpha)$. $r \mathrm{~s} \geq|.08|$ statistically significant at $p<.05, r \mathrm{~s} \geq|.13|$ statistically significant at $p<.001$. * $p<0.05 ;{ }^{* * *} p<0.001$. 
Table 6. Study 3: Means (standard deviations in parenthesis), and inferential statistics for authentic leadership and leader endorsement as a function of experimental condition.

\begin{tabular}{|c|c|c|c|c|c|c|c|}
\hline \multirow[b]{3}{*}{ Variable } & \multicolumn{4}{|c|}{ Means (SDs) in Experimental Conditions } & \multicolumn{3}{|c|}{ Inferential Statistics for Experimental Conditions } \\
\hline & \multicolumn{2}{|c|}{ Low PSA $(N=328)$} & \multicolumn{2}{|c|}{ High PSA $(N=327)$} & \multirow{2}{*}{$\begin{array}{c}\text { PSA } \\
F(1,651)\end{array}$} & \multirow{2}{*}{$\begin{array}{c}\text { CSA } \\
F(1,651)\end{array}$} & \multirow{2}{*}{$\begin{array}{l}\text { Interaction } \\
F(1,651)\end{array}$} \\
\hline & $\begin{array}{c}\text { Low CSA } \\
(N=165)\end{array}$ & $\begin{array}{c}\text { High CSA } \\
(N=163)\end{array}$ & $\begin{array}{c}\text { Low CSA } \\
(N=155)\end{array}$ & $\begin{array}{c}\text { High CSA } \\
(N=172)\end{array}$ & & & \\
\hline Manipulation Check: PSA & $3.29(1.30)$ & $4.06(1.48)$ & $5.65(0.98)$ & $6.22(0.69)$ & $630.34^{* *}$ & $55.60^{* *}$ & 1.33 \\
\hline Manipulation Check: CSA & $2.73(1.49)$ & $5.06(1.41)$ & $3.47(1.59)$ & $6.23(0.85)$ & $77.54^{* *}$ & $551.14^{* *}$ & $4.06^{*}$ \\
\hline Authentic Leadership & $3.02(1.19)$ & $3.97(1.35)$ & $3.90(1.28)$ & $5.80(0.80)$ & $220.21^{* *}$ & $243.11^{* *}$ & $26.92^{* *}$ \\
\hline Leader Endorsement & $2.16(1.60)$ & $4.17(1.88)$ & $3.22(2.00)$ & $6.36(0.96)$ & $158.84^{*}$ & $401.34^{* *}$ & $19.34^{* *}$ \\
\hline
\end{tabular}

Note. PSA = Personal Self-Awareness, CSA = Collective Self-Awareness. All measures were assessed on 7-point scales ranging from 1 (not at all) to 7 (completely). ${ }^{*} p<0.05 ;{ }^{* *} p<0.001$. 


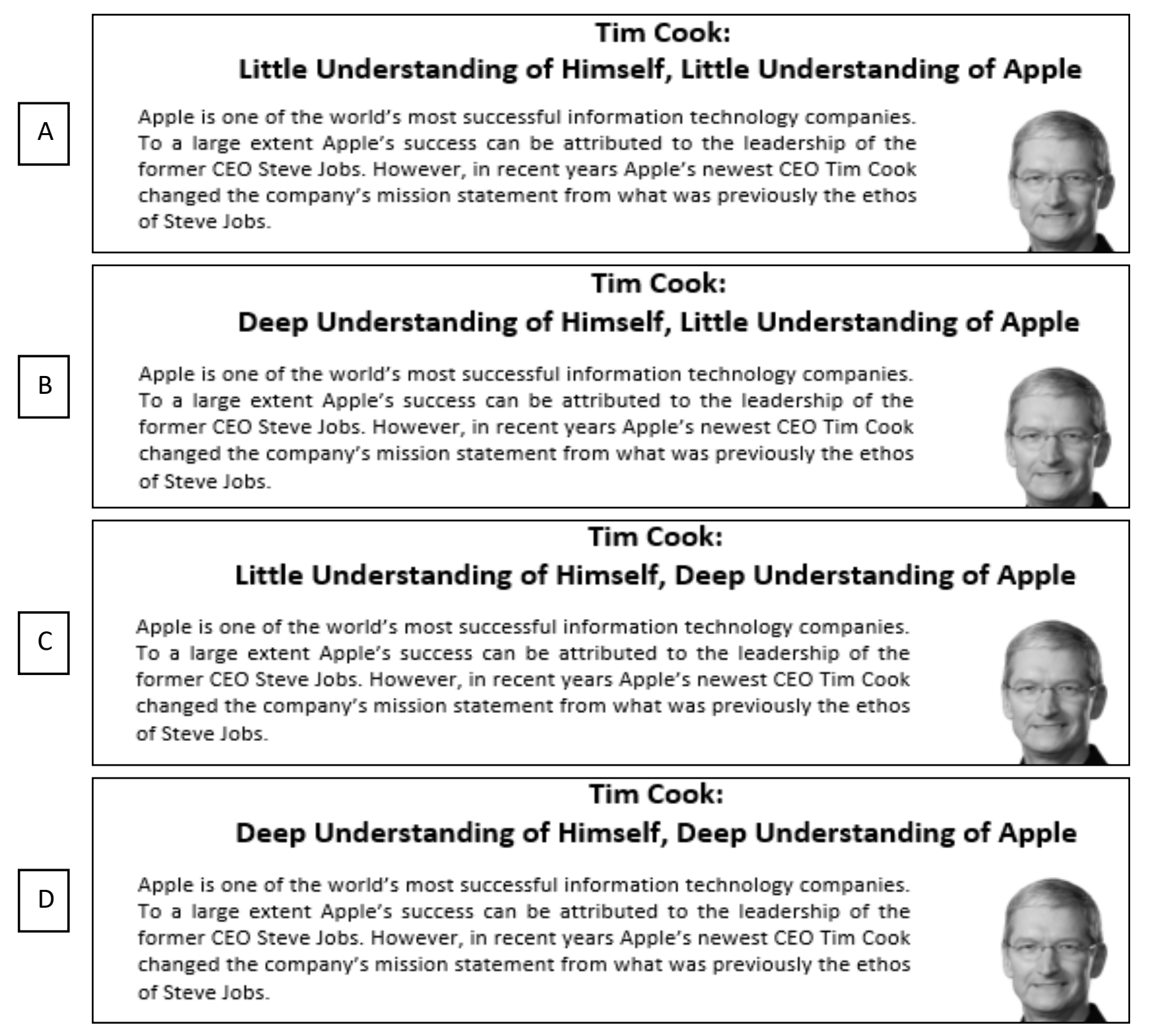

Figure 1. Study 1: Experimental design: Excerpts of the manipulations presenting the title of the online article of the four conditions: (a) low personal / low collective self-awareness, (b) high personal / high collective self-awareness, (c) low personal / low collective selfawareness, and (d) high personal / high collective self-awareness. 


\section{Tim Cook: \\ Little Understanding of Himself, Little Understanding of Apple}

Apple is one of the world's most successful information technology companies. To a large extent Apple's success can be attributed to the leadership of the former CEO Steve Jobs. However, in recent years Apple's newest CEO Tim Cook changed the company's mission statement from what was previously the ethos of Steve Jobs.

Since the change, Apple's new mission has often been questioned, labelled as risky, and argued to be an abrupt shift in identity. Nevertheless, the new mission aims to guide the company's future actions, establish its goals, as well as outline a direction for the future of the company.

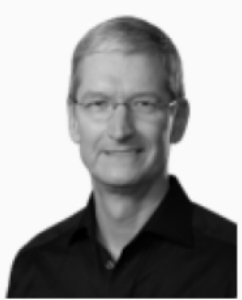

Tim Cook's new mission states that: "Apple designs Macs - the best personal computers in the worid along with OS X, iLife, iWork, and professional software. Apple leads the digital music revolution with its $i P o d s$ and iTunes online store. Apple has reinvented the mobile phone industry with its revolutionary iPhone and App store. Apple is defining the future of mobile media and computing devices with iPad."

As one of the most successful technology companies, Apple gathers a large amount of information from employees, stakeholders, and consumers in an effort to continually improve the customer experience. In the context of recent changes at Apple, including the introduction of its new mission, Apple conducted a representative survey to assess employee perceptions of their new CEO. In this survey, employees indicated their beliefs about Tim Cook's knowledge of various issues related to:

1) The impact of personal events that shaped his life (and the person he has become), and his core personal values.

2) Apple's history (events and achievements that have allowed Apple to thrive), and Apple's core company values.

The survey revealed the following results about employee beliefs of Tim Cook's knowledge about himself and his company:

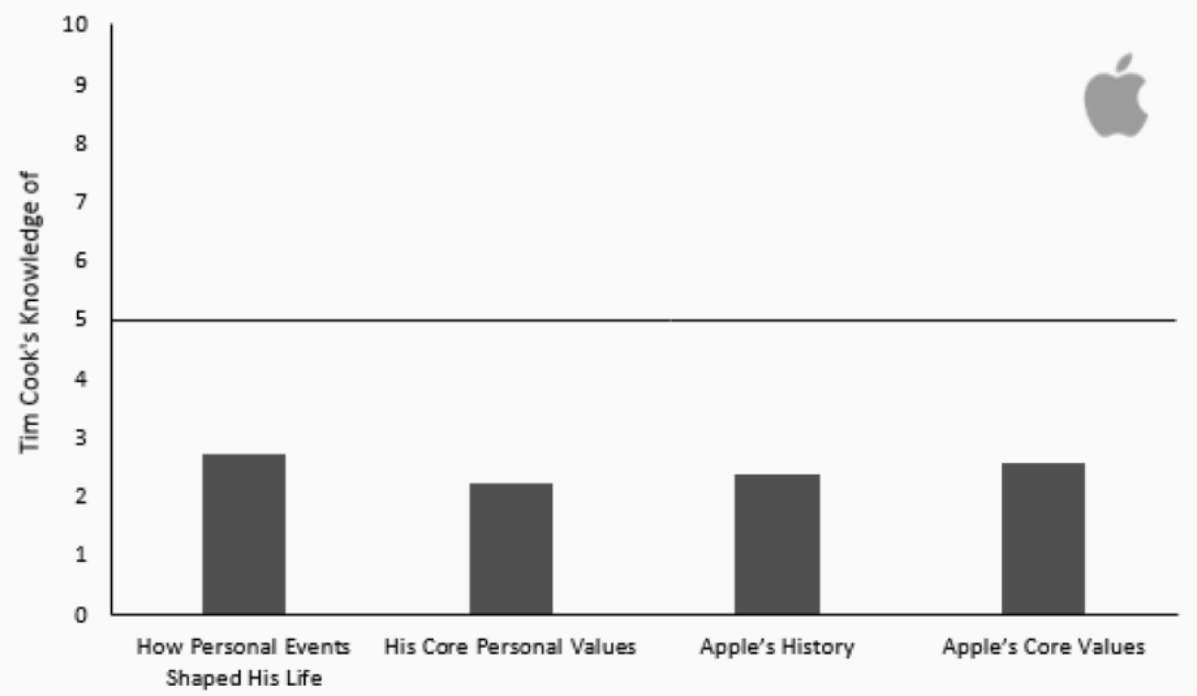

The survey results show that Apple employees believe that Tim Cook has limited knowledge about the influences that shaped him as a person, and limited knowledge about what Apple stands for. To this end, Apple's newest CEO appears to have little understanding of the forces that guide him as an individual, and little understanding of what is unique about his company.

Figure 2. Study 1: Sample experimental stimuli presenting the manipulation of one of the four conditions (here the low personal self-awareness / low collective self-awareness condition). 


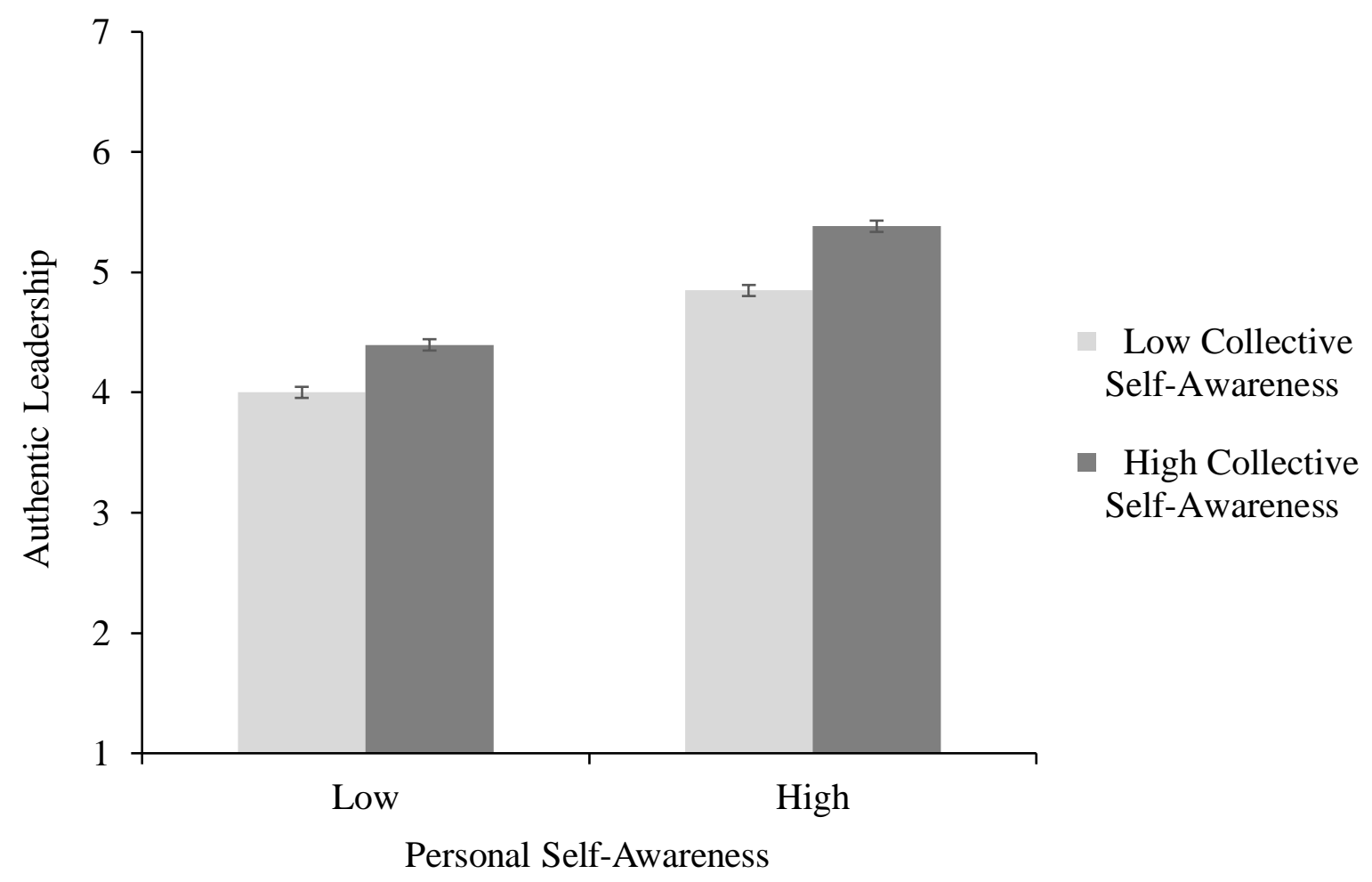

Figure 3. Study 1: Authentic leadership as a function of leaders' personal self-awareness (low vs. high) and collective self-awareness (low vs. high). [Standard errors displayed in error bars] 


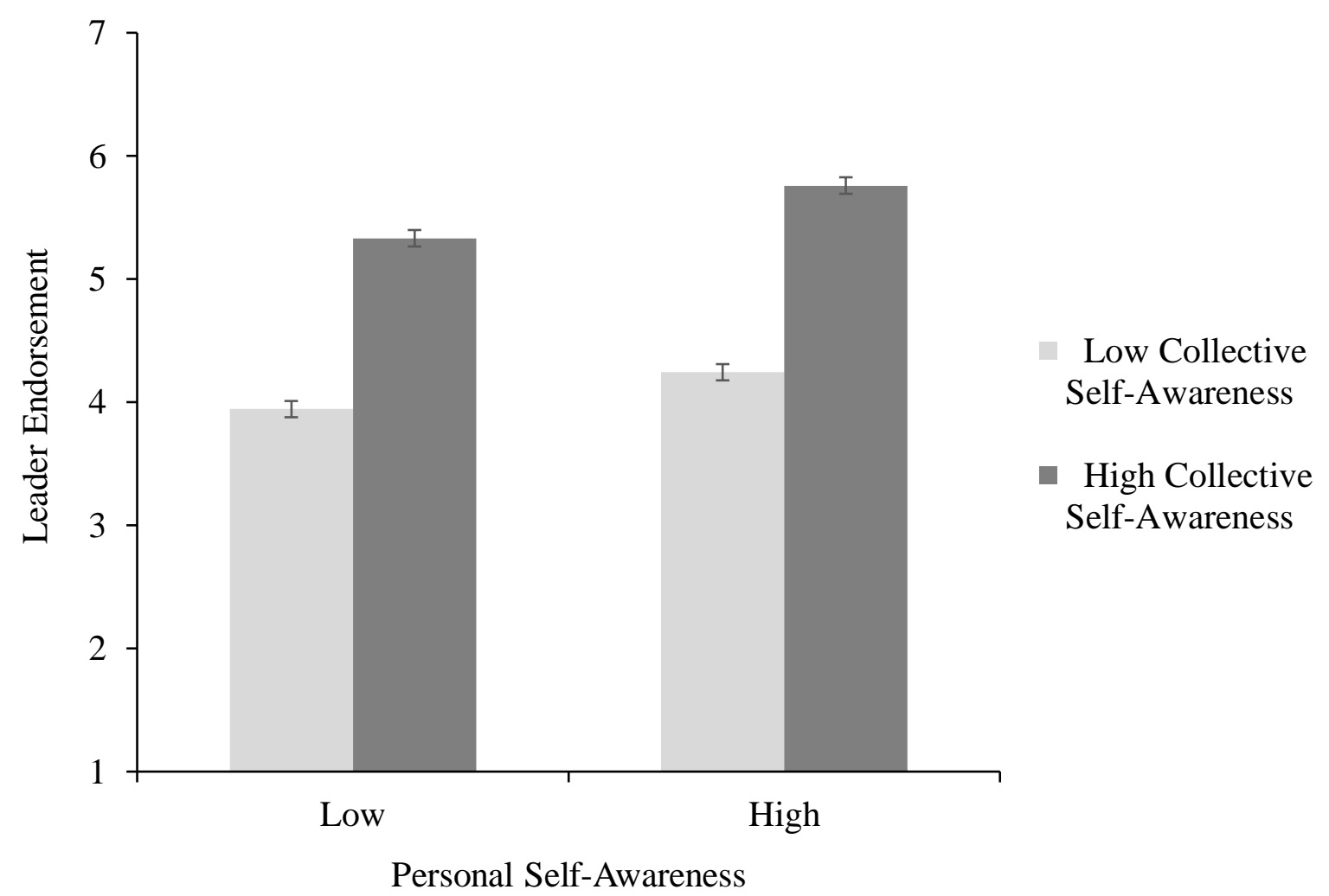

Figure 4. Study 1: Leader endorsement as a function of leaders' personal self-awareness (low vs. high) and collective self-awareness (low vs. high). [Standard errors displayed in error bars] 


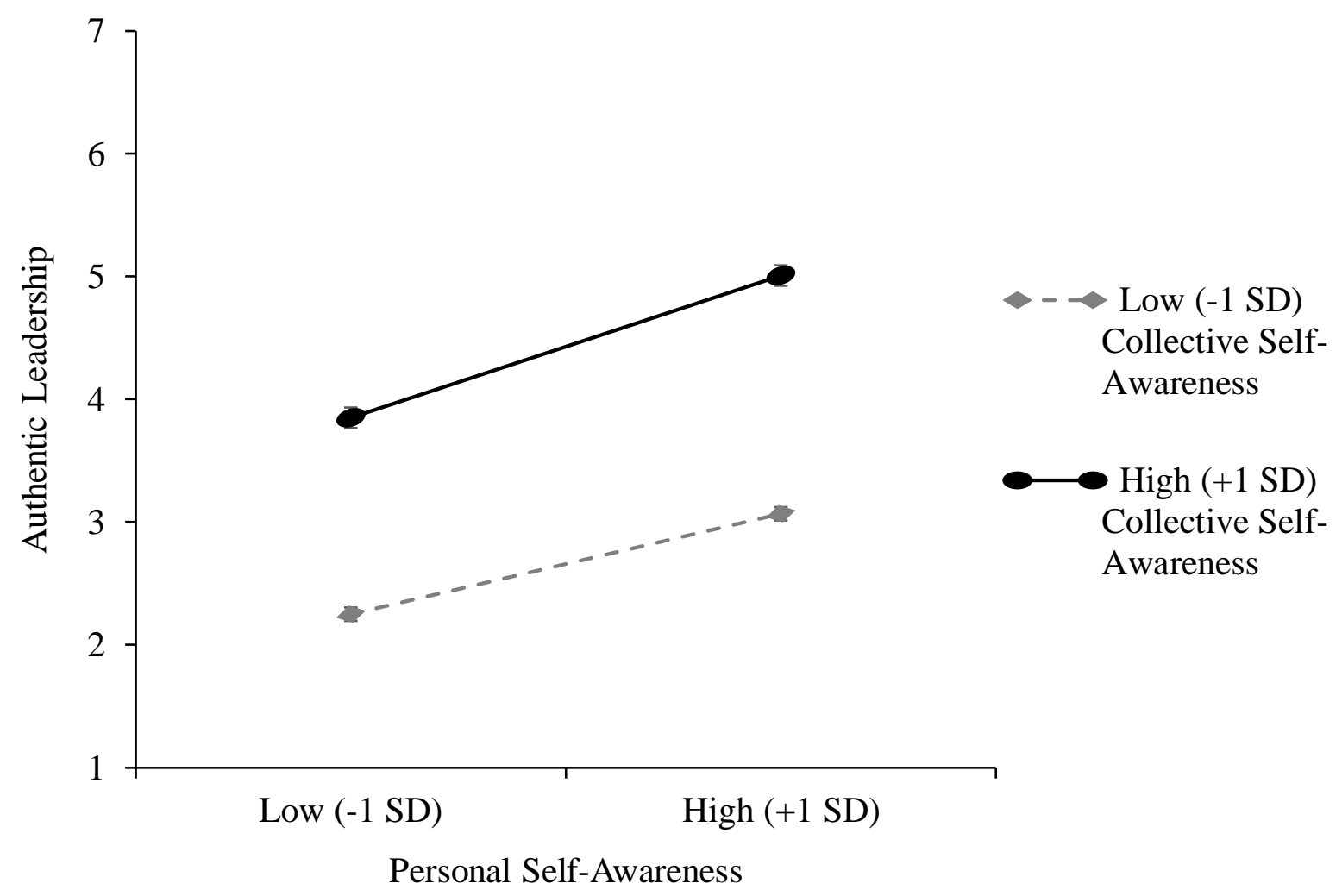

Figure 5. Study 2: Authentic leadership as a function of leaders' personal self-awareness and collective self-awareness. [Standard errors displayed in error bars] 


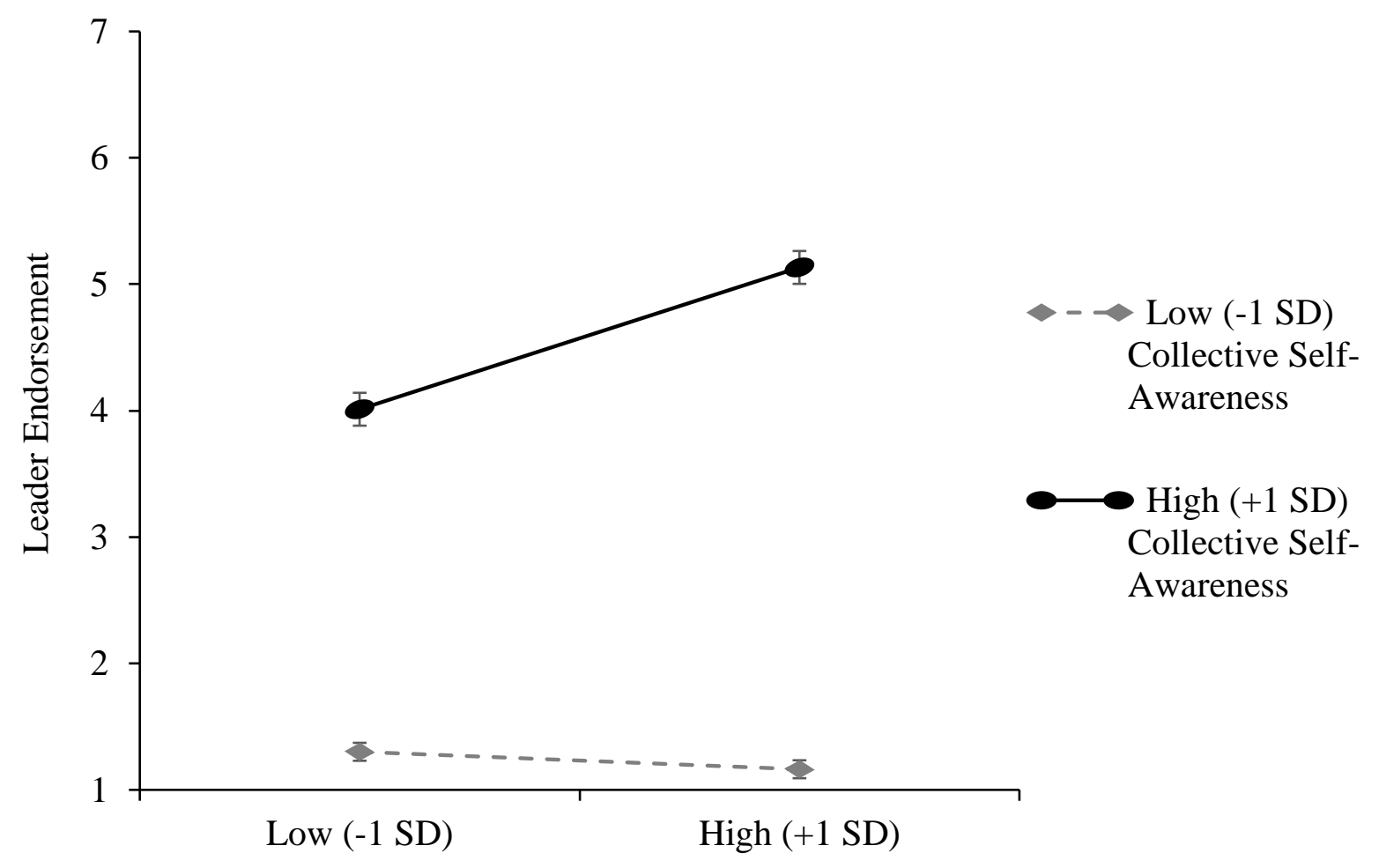

Personal Self-Awareness

Figure 6. Study 2: Leader endorsement as a function of leaders' personal self-awareness and collective self-awareness. [Standard errors displayed in error bars] 


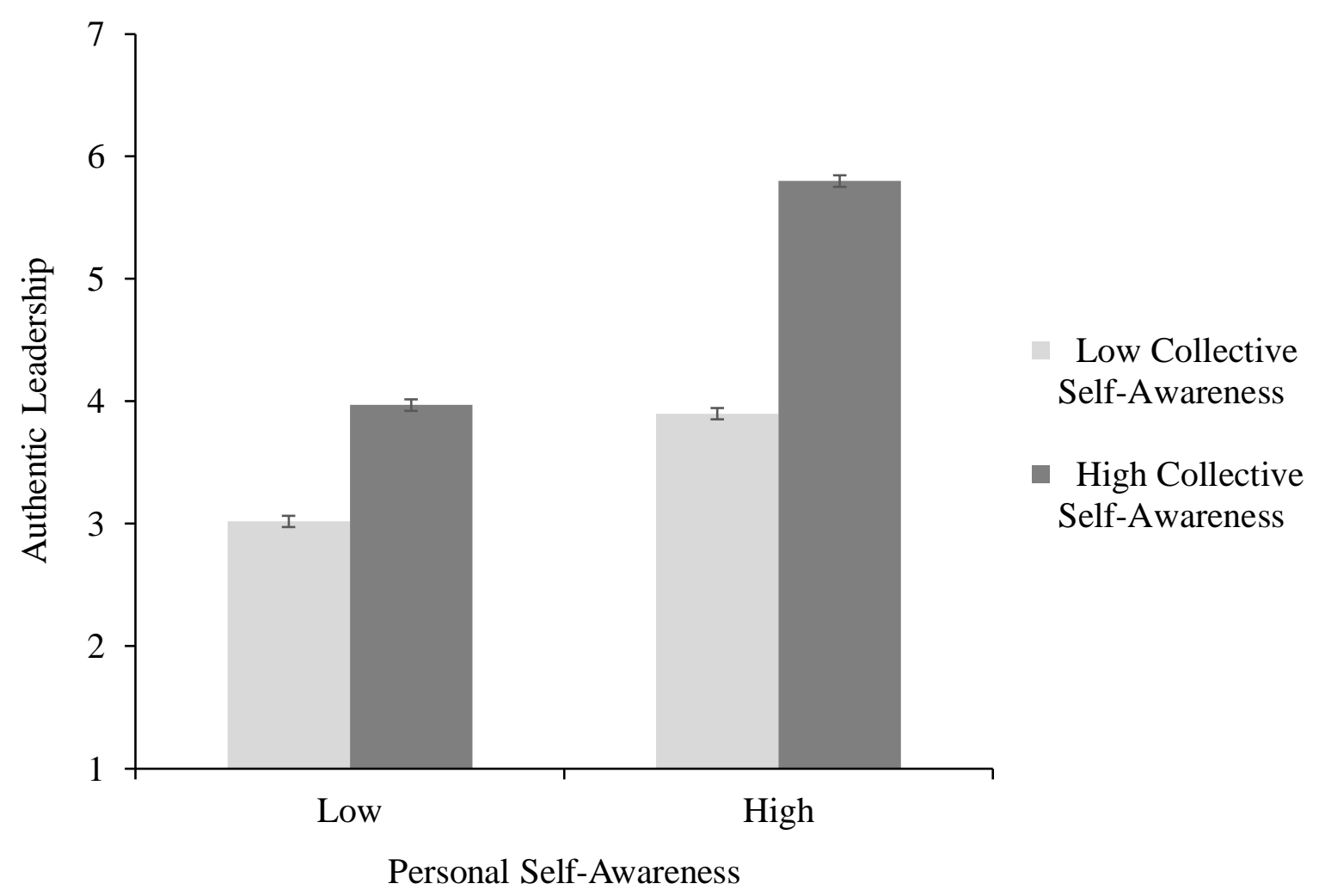

Figure 7. Study 3: Authentic leadership as a function of leaders' personal self-awareness and collective self-awareness. [Standard errors displayed in error bars] 


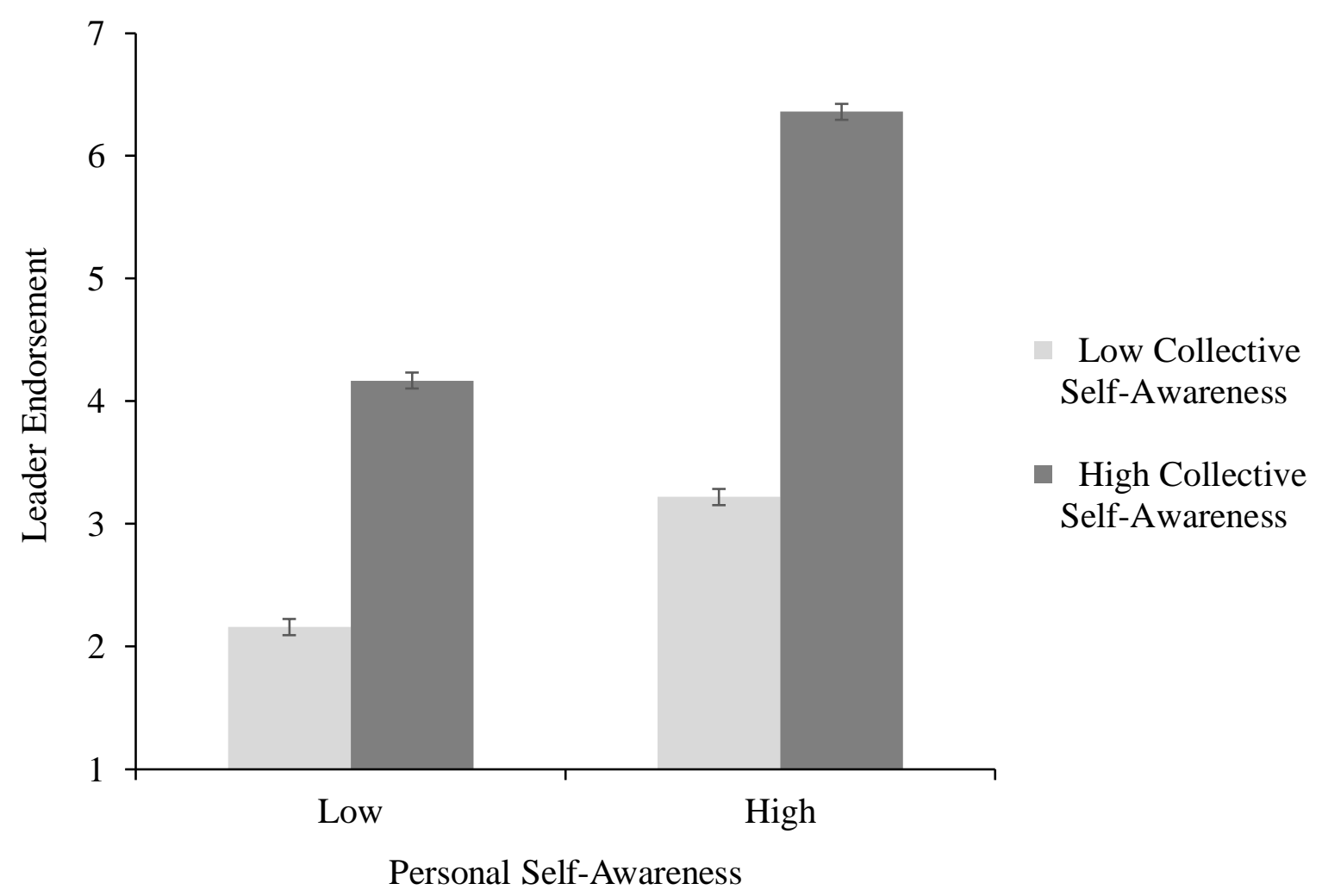

Figure 8. Study 3: Leader endorsement as a function of leaders' personal self-awareness and collective self-awareness. [Standard errors displayed in error bars] 